\section{Molecular switches as photocontrollable "smart" receptors}

\author{
Manuel Natali and Silvia Giordani* \\ Received 16th January 2012 \\ DOI: $10.1039 / \mathrm{c} 2 \mathrm{cs35015g}$
}

This critical review focuses on the development of photochromic compounds as sensors for cations, anions, and biologically important molecules. The review commences with a brief description of photochromism and the strategies to exploit photochromic molecular switches' properties for sensing application. This is followed by a summary of photoswitchable receptors emerged to date and classified according to the photochromic structure they are based on. These include azobenzenes, fulgides, dithienylethenes, dihydroindolizines, chromenes and spiropyrans.

\section{Introduction}

The term photochromism was coined the early fifties by Hirshberg and it indicates a reversible transformation of a single chemical species induced in one or both directions by electromagnetic radiation between two states having different absorption spectra. ${ }^{1}$ In all photoprocesses, a starting material, called an educt, is converted to a product by means of UV, visible or IR irradiation. The back reaction can occur thermally or photochemically. Generally, the photoinduced and reversible change in the absorbance of a photochromic compound is the result of unimolecular reactions. In particular, ring-closing and ring-opening steps, cis-trans and trans-cis isomerizations and intramolecular proton-transfer processes may be invoked.

Trinity College Dublin, School of Chemistry, College Green, Dublin 2, Ireland.E-mail: giordans@tcd.ie; Fax: +353(0)1671 2826; Tel: $+353(0) 18961422$
In all instances the associated transformations produce dramatic changes in one or more properties of the compound such as the emissive behaviour, the ability to absorb visible radiation, the dipole moment and the polarizability of the molecule. As a consequence the macroscopic properties such as refractive index, colour, or phase partitioning may change. ${ }^{2}$ The intriguing nature of existing in two different states that may be switched by means of irradiation has led the scientific community to consider photochromic compounds as the next candidates to be utilized in photonic devices. In particular, they have been extensively employed in supramolecular assemblies such as polymers, ${ }^{3}$ liquid crystals, ${ }^{4}$ light-sensitive eyewear, information recording and optical memory, ${ }^{5}$ and molecular devices. ${ }^{6}$ Of different molecular processes that trigger photochromic phenomena, electrocyclic reactions and cis-trans isomerizations produce the most dramatic changes in the molecular structure and as a consequence in the physical properties of the involved species. Chemical modification of

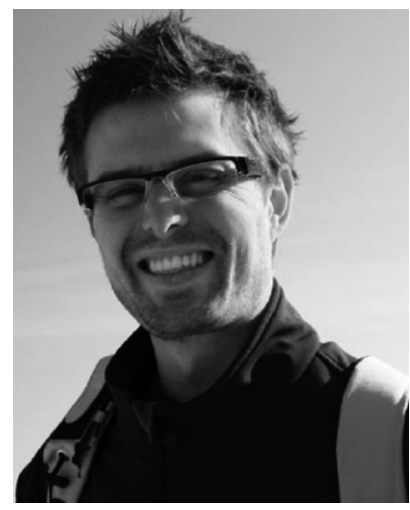

Manuel Natali
Manuel Natali received a Laurea from the University of Trieste, Italy, in 2007 and a PhD in Chemistry from Trinity College of Dublin, Ireland, under the supervision of Dr Silvia Giordani in 2011. His research project focused on the synthesis of novel spiropyran based sensors for the detection of bivalent cations. He is currently carrying out postdoctoral research in collaboration with Prof. Donal F. O' Shea at University College Dublin, Ireland.

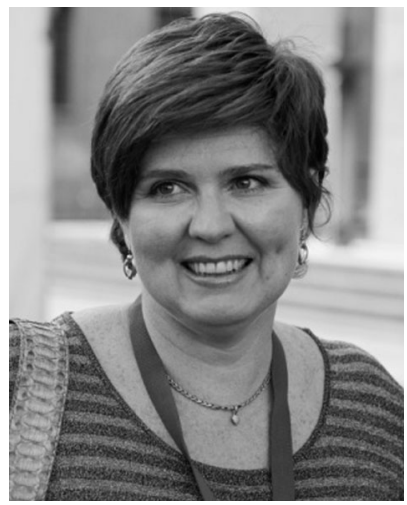

Silvia Giordani
Silvia Giordani received a Laurea from the University of Milan, Italy, and a PhD in Chemistry from the University of Miami, USA. Supported by Marie Curie Fellowships she moved to Trinity College Dublin, Ireland, and later to the University of Trieste, Italy. She is the recipient of the prestigious SFI President of Ireland Young Researcher Award and since 2007 she has been a research lecturer at $T C D$ where she is running an international and interdisciplinary research group. Her research interests focus on the design, synthesis, and characterization of molecular switches and a range of nanomaterials that are intended for applications in smart and responsive bio-related nanotechnologies. 
photochromic compounds offers new possibilities for developing systems that may be suitable for other purposes. Indeed, the incorporation of one or more specific sites for the interaction with other molecular species into a photochromic molecule may afford a system that optically responds to the presence of a guest. For instance, functionalization with an ionophore generates receptors for cations where the uptake and release of the cationic species can be controlled by irradiation with light at different wavelengths. Photoswitchable sensors tailored for detecting the presence of biological molecules such as amino acids and nucleosides have also been reported. The host-guest interaction is always accompanied by an optical signal that allows its detection and, most importantly, may be reversible and fully controlled by photostimulation. This new approach of chemical sensing produces a class of novel compounds that, in principle, may overcome the problem of one-time use sensors, without excluding the possibility of tailoring highly selective ligands that operate in competitive media. Additionally, the changes in physical properties of the host-guest system may be exploited for purposes other than simple substrate detection. For instance, the different affinity of the switchsubstrate complex for a lipophilic environment can be used for the photocontrolled active transport of the analyte through membranes.

In light of the rapid development in this field, it is helpful to summarize recent results concerning molecular switches as photocontrollable receptors. For this purpose this review will survey studies on molecules based on the most important classes of photochromic compounds in the following order: diazastilbenes, fulgides, diarylethenes, dihydroindolizines, chromenes, spirooxazines, and spiropyrans.

\section{Photoswitchable receptors based on diazastilbenes}

Diazastilbenes' properties are due to a cis-trans isomerization mechanism. These compounds differ from stilbenes because of a $\mathrm{N}=\mathrm{N}$ double bond instead of a $\mathrm{C}=\mathrm{C}$ double bond. They have relatively simple structures that undergo trans-cis isomerization in solution if irradiated with light of an appropriate wavelength. The isomerization step consists of a $180^{\circ}$ rotation about their $\mathrm{N}=\mathrm{N}$ double bond that produces two chemical species, the $Z$ and $E$ isomers, that have different absorption spectra. In particular the $E$ isomer is converted into the $Z$ by means of UV irradiation in the range of $360-370 \mathrm{~nm}$, where the first absorbs mainly. Since the cis isomer absorbs in the visible region at $430-440 \mathrm{~nm}$, irradiation with visible light in this region will trigger the reversion to the trans isomer. ${ }^{7}$ The same result may be achieved thermally. ${ }^{8}$ An example of this behaviour is shown in Scheme 1. Since their appealing properties, diazastilbene may be used for reversibly triggering the properties of different materials. The geometrical transformations of

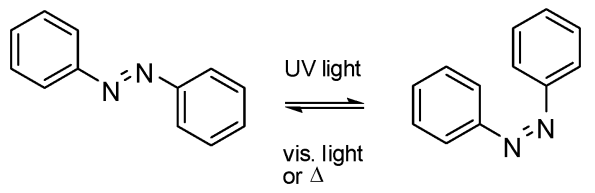

Scheme 1 Conversion of $E$-diazastilbene into and $Z$-diazastilbene via trans-cis isomerization driven by irradiation.

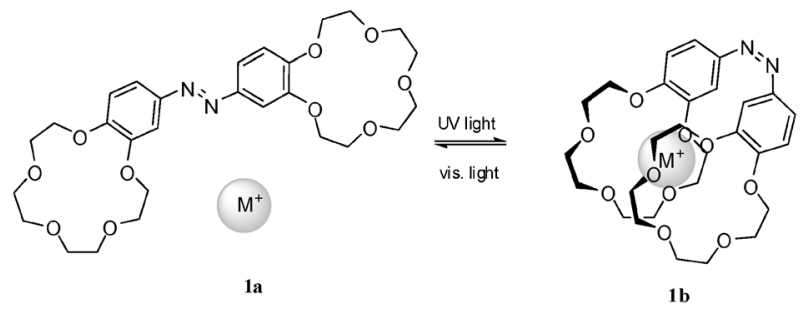

Scheme 2 Reversible cation binding and release by compound 1a actuated by UV and visible irradiation, respectively. UV light produces trans-cis isomerization of $\mathbf{1 a}$ into $\mathbf{1 b}$ which is able to bind $\mathrm{M}^{+}=\mathrm{K}^{+}, \mathrm{Na}^{+}$and $\mathrm{Rb}^{+}$. The cation release is affected by visible light irradiation that converts $\mathbf{1 b}$ into $\mathbf{1 a}$.

diazastilbenes incorporated in polymers may result in dramatic changes in properties such as swelling, ${ }^{9}$ wettability,${ }^{10}$ viscosity ${ }^{11}$ and solubility. ${ }^{12}$

Several examples of azobenzenes (or diazastilbenes) modified in order to obtain photoswitchable ion receptors have been synthesized. Shinkai and co-workers reported light-driven membrane transport of $\mathrm{K}^{+}, \mathrm{Na}^{+}$and $\mathrm{Rb}^{+}$cations mediated by the azobis(benzo-15-crown-5) 1a. ${ }^{13}$ This derivative bears two crown ethers, one on each benzene ring. Crown ethers are known for their capability of complexing alkali, alkaline earth, heavy and other metals and/or ammonium ions. ${ }^{14,15}$ In the presence of $\mathrm{K}^{+}, \mathrm{Na}^{+}$and $\mathrm{Rb}^{+}$the trans isomer 1a undergoes trans-cis isomerization that affords the cis isomer $\mathbf{1 b}$. Owing to the reduced distance between the two crown ethers, this isomer is able to bind the metal cations working as tweezers. The cationic guest release is effected by means of irradiation with visible light that produces the conversion of $\mathbf{1 b}$ into $\mathbf{1 a}$ (Scheme 2).

A similar approach was used by Akabori and co-workers to investigate the cation extraction ability of the diazastilbene analogue 2a (Scheme 3) from an aqueous solution containing monovalent cations like $\mathrm{Na}^{+}, \mathrm{K}^{+}, \mathrm{Li}^{+}, \mathrm{Rb}^{+}$and $\left[\mathrm{Me}_{4} \mathrm{~N}^{+}\right] \cdot{ }^{16}$ They found that irradiation with UV light of a solution containing 2a increases the amount of cation extracted by the compound. This phenomenon was explained as the result of the cis-trans photoisomerization of $\mathbf{2 a}$ into $\mathbf{2 b}$ that decreases the distance between the binding sites present on the molecule: a crown ether and an alkyl phosphoric acid. Thus the photochromic compound can act as tweezers able to grab a cation.

The azobenzene-bridged crown ether 3a was synthesized by Shinkai and collaborators. ${ }^{17}$ In this analogue the diazastilbene phenyl rings are linked to the same crown ether.

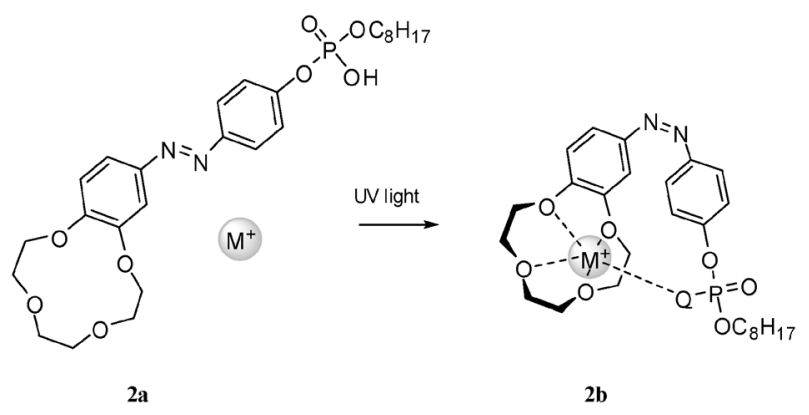

Scheme 3 Trans-cis isomerization of $\mathbf{2 a}$ into $\mathbf{2 b}$ by UV light irradiation with consecutive binding of a metal cation $\mathrm{M}^{+}=\mathrm{Na}^{+}, \mathrm{K}^{+}, \mathrm{Li}^{+}, \mathrm{Rb}^{+}$ and $\mathrm{Me}_{4} \mathrm{~N}^{+}$. 


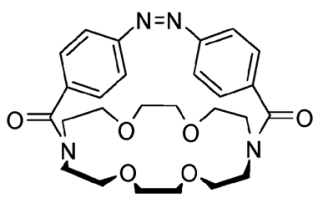

3a

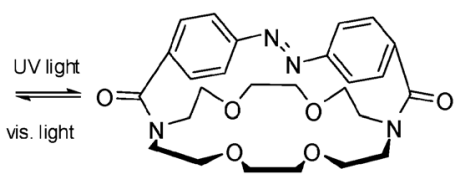

$\mathbf{3 b}$
Scheme 4 Reversible cis-trans photoisomerization of 3a into $\mathbf{3 b}$ by $\mathrm{UV}$ and visible irradiation.

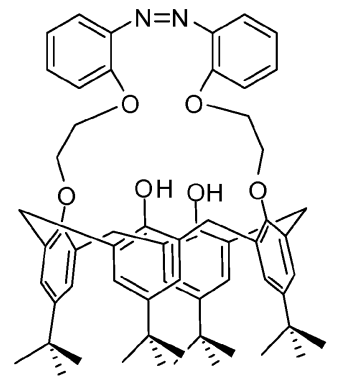

$4 \mathbf{a}$

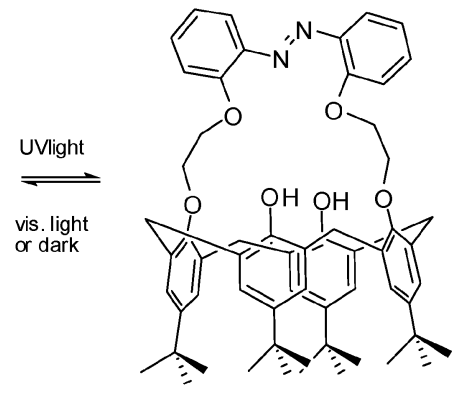

$4 \mathbf{b}$
Scheme 5 Reversible cis-trans and trans-cis photoisomerization of $\mathbf{4 a}$ into $\mathbf{4 b}$ by UV and visible irradiation/storage in the dark, respectively.

The photoisomerization of the diaza compound from cis to trans produces a stretching of the macrocycle. Thus the inner area of the crown ether can be modified by means of irradiation with light at different wavelengths driving its selectivity toward cations with different size. For instance they found that the cis isomer $\mathbf{3} \mathbf{a}$ has a wider inner area than the trans analogue $\mathbf{3 b}$ as a consequence of the more compact and constrained geometry of the cis form (Scheme 4). Thus the cis isomer should prefer large cations while the trans analogue should prefer smaller ones. The result of the solvent extraction efficiency of a series of monovalent cations with 3a was in the order of $\mathrm{K}^{+}>\mathrm{Na}^{+}>$ $\mathrm{Rb}^{+}>\mathrm{Li}^{+}$and $\mathrm{Cs}^{+}$. The corresponding trans analogue $\mathbf{3 b}$ extracted the same cations in the order of $\mathrm{K}^{+}>\mathrm{Na}^{+}>$ $\mathrm{Li}^{+}>\mathrm{Rb}^{+}$and $\mathrm{Cs}^{+}$. Large alkali metal ions such as $\mathrm{Rb}^{+}$ and $\mathrm{Cs}^{+}$are hardly extracted by the trans isomer while small cations like $\mathrm{Li}^{+}$are not extracted by the cis isomer.

Pipoosananakaton and collaborators synthesized new derivatives of $p$-tert-butylcalix[4]arenes capped with a diazastilbene. ${ }^{18}$ Compound 4a shown in Scheme 5 is one of these derivatives. They found that the stable isomer is the cis one, due to the rigidity of the calixarene ionophore. After irradiation with UV light, a mixture of cis and trans $\mathbf{4 b}$ isomers were obtained. The trans form reverts back to cis conformation upon irradiation with visible irradiation or thermal fading after storage in the dark. Complexation analysis with sodium and potassium salts showed that $\mathrm{Na}^{+}$preferred to bind the cis form $4 \mathbf{a}$ while $\mathrm{K}^{+}$ preferred to bind the trans isomer $\mathbf{4 b}$.

\section{Photoswitchable receptors based on fulgides}

The oldest known photochromic organic compounds are fulgides. Their remarkable fatigue resistance and the possibility to modify their photochromic properties by tailoring their structures has attracted interest both academically and commercially. ${ }^{19}$

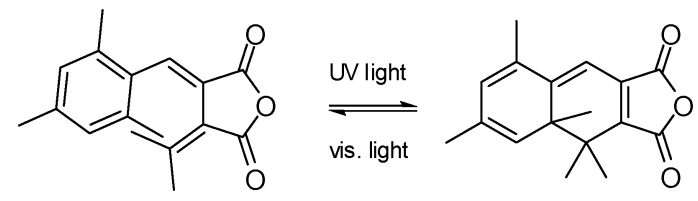

Scheme 6 Photochromic cyclization of a general fulgide to its corresponding dihydronaphthalene modulated by UV and visible irradiation.

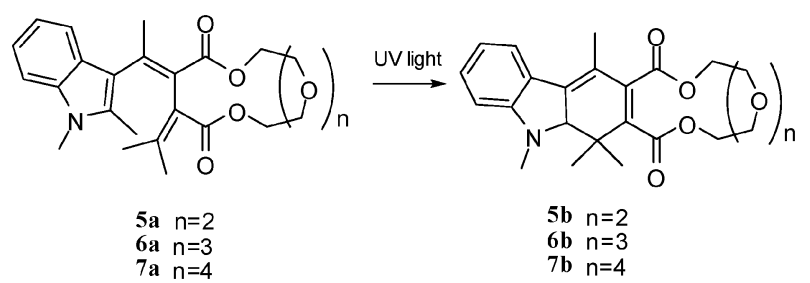

Scheme 7 Photoisomerization of fulgenates 5a, 6a and 7a into their corresponding closed isomers $\mathbf{5 b}, \mathbf{6} \mathbf{b}$ and $\mathbf{7 b}$ driven by UV irradiation.

They find applications mainly in non-linear optical switching ${ }^{20}$ and optical recording memories. ${ }^{21,22}$ Their structure consists of a cyclic anhydride with two exo-methylenes. To be photochromic, one of the two methylenes has to be attached to an aromatic ring, thus the resulting 1,3,5-hexatriene undergoes a $6 \pi$-electrocyclization that affords a dihydronaphthalene (Scheme 6).

Despite their appealing features, only a few examples of fulgides bearing an ionophore suitable for ion sensing were found in the literature.

The photochromism of three fulgenates bridged with tri- (5a), tetra- (6a), and pentaethyleneglycoles (7a) as binding sites and the interactions with $\mathrm{Li}^{+}, \mathrm{Na}^{+}$and $\mathrm{K}^{+}$of their colourless and coloured forms were reported. ${ }^{23}$ Compound $\mathbf{5 a}$ and its closed isomer $\mathbf{5 b}$ did not bind cations effectively because of the small size of their ionophore. The association constant for $\mathrm{Na}^{+}$was large for $\mathbf{6 a}$ and that for $\mathrm{K}^{+}$was large for 7a. The photoisomerization of $\mathbf{6 a}$ and $7 \mathbf{a}$ into their corresponding closed forms $\mathbf{6 b}$ and $\mathbf{7 b}$ produced a drop in the affinities for sodium and potassium. These phenomena were given by the higher flexibility of the open isomers that guarantees a better interaction with the cations. The fulgenates $\mathbf{5 , 6}$, and $\mathbf{7}$ are depicted in Scheme 7.

The two fulgides 8 and 9 (Scheme 8) bearing a benzo-18crown- 6 moiety as ionophore have been synthesized ${ }^{24}$ and the interactions with alkali and alkaline earth metal cations were studied. The decoloration rate of the closed isomers of the two derivatives evidently decreases upon selective cation binding. A hypsochromic shift of the absorption of the open and closed forms by up to $50 \mathrm{~nm}$ was also observed upon complexation.

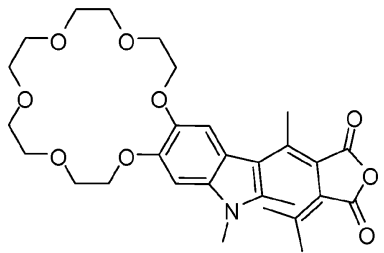

8

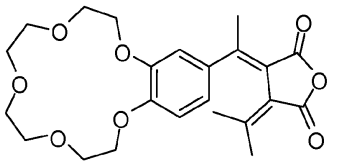

9
Scheme 8 Benzo-18-crown-6 indolylfulgide 8 and benzo-15-crown-5modified fulgide $\mathbf{9}$. 


\section{Photoswitchable receptors based on diarylethenes}

By replacing the phenyl rings of stilbene with thiophene rings and introducing a pentatomic ring that prohibits the cis-trans isomerization of the ethylene, a photochromic compound that undergoes cyclization to produce a thermally stable dihydrotype product is generated. ${ }^{25,26}$ This class of compounds is the well known family of diarylethenes. A general example is shown in Scheme 9.

Switching of host-guest interactions by photoirradiation potentially enables active transportation of guest molecules or detection of certain chemical species. The photochromic properties of diarylethenes can also be exploited for such purposes as their switching unit may be modified with appropriate functional groups suitable for interacting with a chemical guest.

Irie and co-workers reported in several publications the chelation of different metal cations by means of the modified diarylethenes 10a, 11a and 12a where two crown ether units with different inner area were introduced in the molecular skeleton. ${ }^{27-29}$ When the crown moieties are parallel to each other in the open forms, they are able to capture, in a tweezer like manner, a large metal cation. The photoisomerization to the closed isomers $\mathbf{1 0 b}, \mathbf{1 1} \mathbf{b}$ and $\mathbf{1 2 b}$ carried out by irradiation with UV light $(330 \pm 70 \mathrm{~nm})$ forces the two crown units to separate from each other, impeding metal chelation. Thus, if the switchable unit is open and chelating a metal cation, by irradiation with UV light the cation is released. Irradiation with light at wavelengths higher than $450 \mathrm{~nm}$ triggers the ring opening. Thus, following structural rearrangement that brings the crown ether moieties in close proximity, the re-uptake of the metal cation takes place (Scheme 10).

The same authors studied the bi-phasic solvent extraction of alkali metal picrates by the three compounds mentioned above. An estimate of the amount of cations extracted by the diarylethenes was given by the absorption decrease of picrates in the aqueous phase. They noticed that compound 11a, bearing a
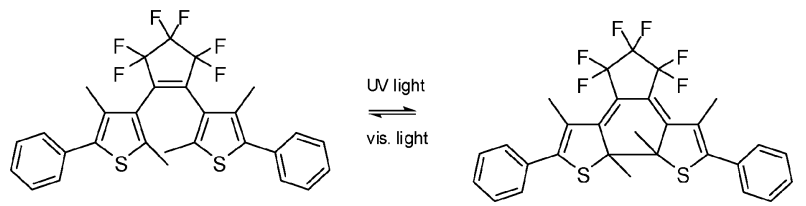

Scheme 9 Photochromic cyclization of a diarylethene to its corresponding closed-ring form modulated by UV and visible irradiation.

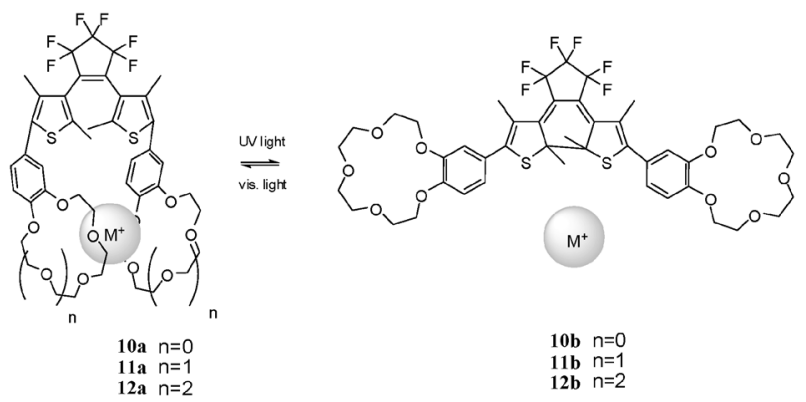

Scheme 10 Photoresponsive tweezers based on crown ether functionalized diarylethenes.

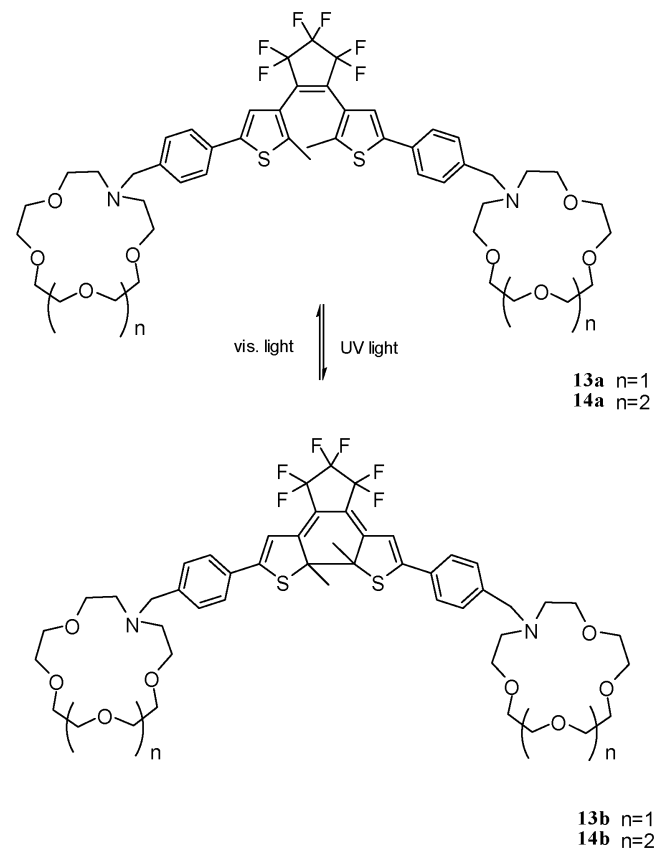

Scheme 11 Photochromism of crown ether modified diarylethenes synthesized by Kawai.

benzo-15-crown-5 ether, extracted $50 \%$ of potassium and rubidium picrates from the aqueous phase. After irradiation with UV light the amount extracted fell to $20 \%$. A similar result was observed for the extraction of caesium picrate extracted by compound 12a bearing a benzo-18-crown-6 ether which decreased dramatically after photoconversion to the closed isomer $\mathbf{1 2 b}$ by irradiation with light at $330 \mathrm{~nm}$. Compound 10a possesses the smallest ionophores in the series and its extractability was studied as well but the photoeffect was not remarkable.

A novel series of diarylethenes (compounds 13a, 14a and their corresponding photoproducts $\mathbf{1 3 b}$ and $\mathbf{1 4 b}$ depicted in Scheme 11) bearing two crown ether units linked to the switchable core via methylenic bridges were synthesized. ${ }^{30}$ This approach affords structures that are similar to 10a, 11a and 12a but with a slightly increased flexibility of the ionophores. The phase extraction of lithium, sodium, potassium, caesium and rubidium picrates was studied and both the photoisomers 13a and 14a showed good capability of extracting all the cations with marked preference for $\mathrm{K}^{+}$while no extraction of $\mathrm{Li}^{+}$was observed.

Two new diarylethenes 15a and 16a with terpyridine units (tpy) attached via a phenylene linker to the thiophene rings were developed. ${ }^{31}$ This compound showed good photochromic properties. First of all, the tpy residues are fluorescent. If the switchable unit is in its open form an intense fluorescent band with maximum intensity at 467 and $458 \mathrm{~nm}$ is visible upon excitation at $365 \mathrm{~nm}$. Irradiation with UV light triggers the ring closure of the diarylethene units affording the isomers $\mathbf{1 5 b}$ and $\mathbf{1 6 b}$. As a consequence of the efficient energy transfer from the terpyridine units to the aromatic system of the closed switch, emissions undergo a drastic quench (Fig. 1).

The presence of $\mathrm{Mn}^{2+}, \mathrm{Co}^{2+}, \mathrm{Ni}^{2+}, \mathrm{Cu}^{2+}, \mathrm{Zn}^{2+}, \mathrm{Pb}^{2+}$ caused changes to the spectral properties of the ligands. It is 


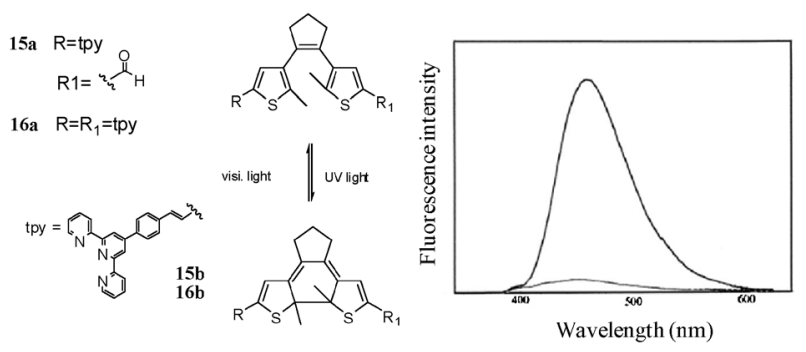

Fig. 1 Schematic representation of the photoconversion of $\mathbf{1 5 a}$ and 16a into 15b and 16b. Fluorescence spectra of 16a before and after irradiation with UV light $\left(\lambda_{\mathrm{exc}}=365 \mathrm{~nm}\right)$. Adapted from ref. 31 .
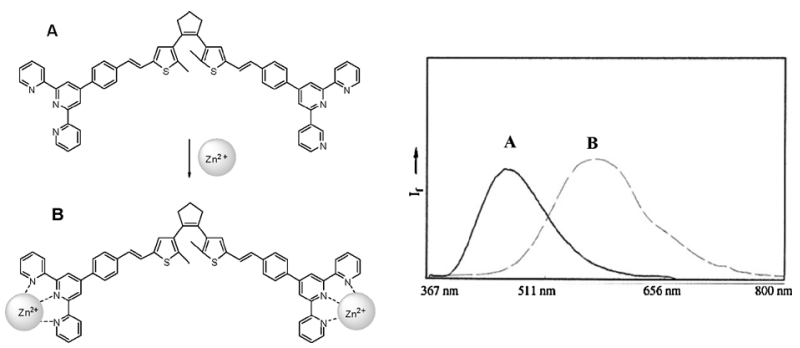

Fig. 2 Schematic representation of the interaction between 16a and $\mathrm{Zn}^{2+}$. Fluorescence spectra of 16a before (A) and after addition of $\mathrm{Zn}^{2+}$ (B) $\left(\lambda_{\text {exc }}=365 \mathrm{~nm}\right)$. Adapted from ref. 31 .

worth noting that the presence of zinc in a solution containing the open form 16a caused a dramatic redshift of $100 \mathrm{~nm}$ in the emission maximum due to the coordination of the metal cation to the tpy units (Fig. 2). Thus, this analogue may be considered a potential candidate for zinc sensing.

A stunning example of metal binding ability tuned by switching between the open and closed isomers of a functionalized diarylethene was reported. ${ }^{32}$ The two thiophene rings of the molecular switch 17a are functionalized with a chelating crown ether and an electron withdrawing formyl group, respectively. Ligation of $\mathrm{Ag}^{+}, \mathrm{Na}^{+}$and $\mathrm{Ca}^{2+}$ by the photogenerated closed isomer $\mathbf{1 7 b}$ gave a decrease of four orders of magnitude in the binding affinities for these metals with respect to the complexation by the open isomer 17a (Scheme 12).

The lowered binding ability is the result of a decrease of the electronic density in the crown ether of the closed form due to the communication through an extended aromatic system between the ionophore and the electron withdrawing formyl group on the other thiophene ring. If the diarylethene is open, the conjugation through the molecule skeleton is disrupted and the electronic effect of the formyl group is not allowed to take place. Thus, the higher electronic density of the ionophore in the open form results in a better interaction with a cationic guest. In this way the uptake/release of metal cations may be affected by switching the photochromic core of this system with UV and visible light.

The synthesis of an organoboron based diarylethene 18a and the studies on its selective interaction with fluoride anions were reported. ${ }^{33}$ They observed that this compound, functionalized with two dimesitylboryl residues on the thiophenic rings, responded to UV irradiation with the appearance of a new absorption band at $655 \mathrm{~nm}$ indicating the formation of the closed isomer $\mathbf{1 8 b}$. As shown in Scheme 13, the conversion
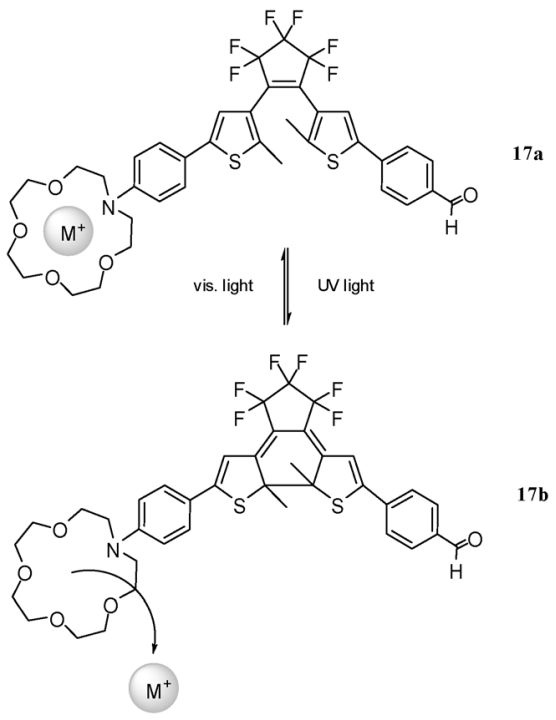

Scheme 12 Schematic representation of the cation release/uptake by compound 17a after its photoisomerization to the closed form $\mathbf{1 7} \mathbf{b}$ driven by irradiation with UV and visible light.

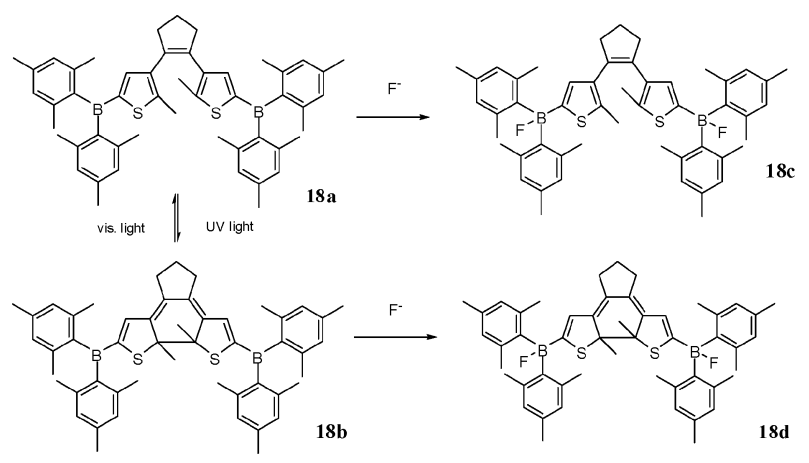

Scheme 13 Interconversion between $18 \mathbf{a}$ and $\mathbf{1 8 b}$ controlled by UV and visible irradiation and formation of adducts $\mathbf{1 8 c}$ and $\mathbf{1 8 d}$ after addition of $\mathrm{F}^{-}$.

was reversible upon irradiation with visible light and the starting material was readily regenerated under these conditions. Additionally, both isomers responded to the presence of $\mathrm{F}^{-}$ with dramatic shifts in their absorption spectra indicating the formation of two adducts $\mathbf{1 8 c}$ and $\mathbf{1 8 d}$. The most dramatic absorption change was observed after the addition of $\mathrm{F}^{-}$to a THF solution of 18a whose absorption maximum blueshifted from 655 to $490 \mathrm{~nm}$ due to the formation of $\mathbf{1 8 d}$.

Switching of host-guest interactions between a diarylethene functionalized with two boronic acid units and saccharides has been reported. ${ }^{34}$ Derivative 19a undergoes reversible photoisomerization upon UV irradiation to the corresponding closed ring isomer 19b. As expected, the latter could be converted back to the starting material by means of visible light. The open form could exist in two conformations, parallel and anti-parallel, which exchange rapidly at room temperature. In the parallel conformer, the two thiophene rings and the two boronic acid groups face each other in a tweezer like fashion. Thus, the two boronic moieties may form linkages with a saccharide, generating a chiral complex which is $\mathrm{CD}$ active and whose chirality is due to the sugar configuration. 


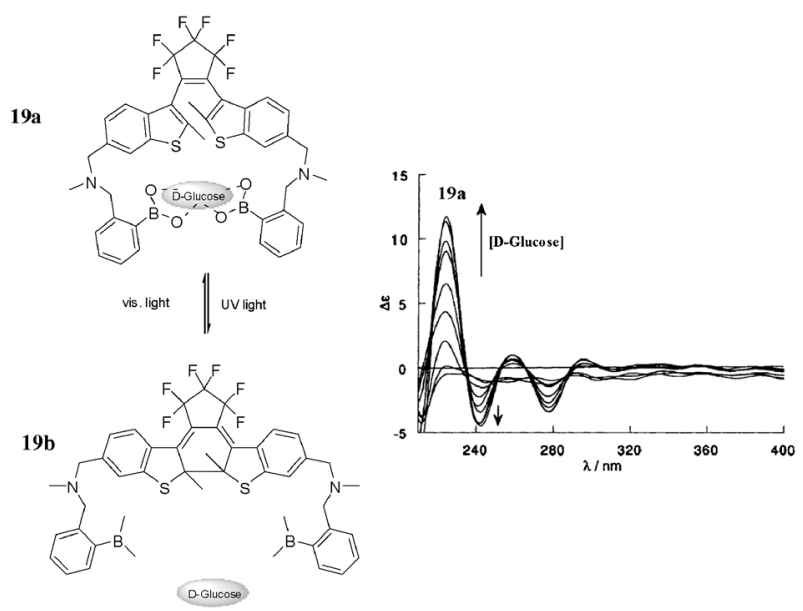

Fig. 3 Schematic representation of the switchable interaction between 19a and D-glucose. CD spectra change upon addition of D-glucose $\left(7 \times 10^{-4} \mathrm{M}\right)$ to a solution of $19 \mathrm{a}\left(1.4 \times 10^{-5} \mathrm{M}\right)$ in EtOH-tris- $\mathrm{HCl}$ (pH 7.8). Adapted from ref. 34.

Indeed, after addition of D-glucose to an ethanolic solution of 19a, a drastic increase of the $\Delta \varepsilon$ at $224 \mathrm{~nm}$ indicative of the diarylethene-saccharide complex formation was observed (Fig. 3). This value decreases by $60 \%$ after irradiation of the same solution with UV light. This phenomenon is the result of the ring closure of the diarylethene which separates the two boronic functionalities and impedes the interaction with the glucose molecule. The $100 \%$ of the $\Delta \varepsilon$ value is restored after irradiation with visible light.

\section{Photoswitchable receptors based on dihydroindolizines}

The photochromism of dihydroindolizines or DHIs was first reported in $1979 .{ }^{35}$ The photochromic behaviour is based on a reversible pyroline opening upon UV irradiation that converts a colourless closed form into a betaine. The closed form is regenerated by a thermal path and involves the 1,5-electrocyclization of the betaine (Scheme 14). Owing to their features they have been considered as suitable materials for ophthalmic lenses, data storage photoswitches, dental filling materials, ${ }^{36,37}$ IR-sensitive photoswitchable materials, ${ }^{38}$ and DNA markers. ${ }^{39}$

A new approach for tuning physical properties of DHIs via host-guest interactions has been reported and involves the complex formation in crown, calixarene and ether containing molecular switches. ${ }^{40-42}$ Two examples are molecules 20a and $21 \mathrm{a}^{42}$ where a dihydroindolizine core is attached through a polyethyleneglycole linker, the ionophore, to a quinoline and to an additional indolizine unit. Photoinduced ring opening by means of UV light causes the formation of the betaine isomers 20b and 21b which revert back thermally (Scheme 15).

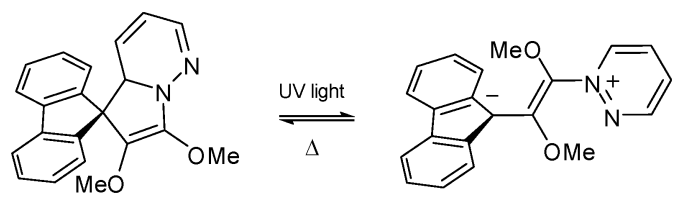

Scheme 14 Reversible photochromic conversion of a dihydroindolizine to its corresponding betaine by UV irradiation.
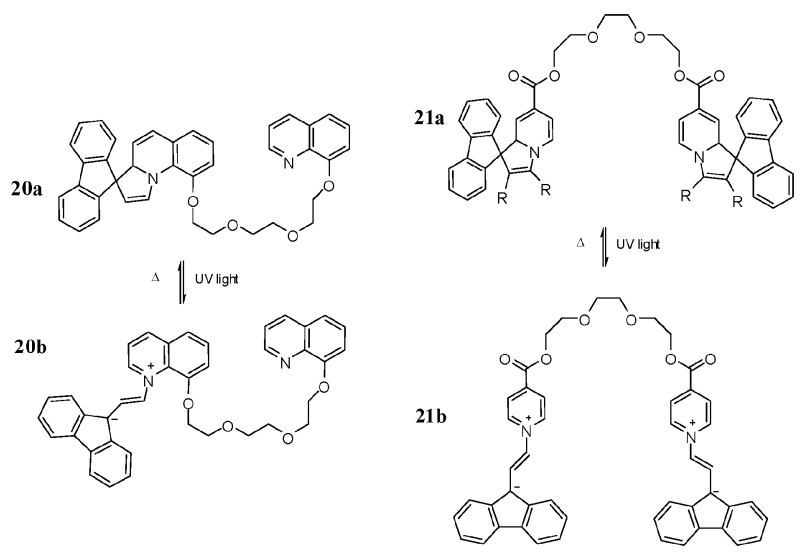

Scheme 15 Interconversion between 20a and 21a controlled by UV irradiation and thermal fading of $\mathbf{2 0 b}$ and $\mathbf{2 1 b}$ to their corresponding starting materials.

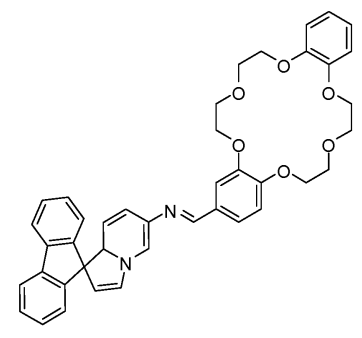

22

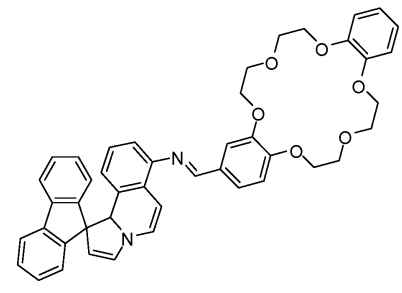

23
Scheme 16 Dihydroindolizines 22 and 23 bearing crown ether moieties as cation ligand sites.

Complexation of alkaline cations by the different isomers produces only small changes in the spectral properties of these molecules due to the high flexibility of the ionophore.

More remarkable changes were observed for compounds $\mathbf{2 2}$ and 23 containing crown ether units as ligands (Scheme 16). ${ }^{40}$ Compound 23 and the corresponding betaine responded to the addition of alkali and alkaline earth metal cations with bathochromic shifts in their UV spectra. Emission spectra underwent an intensity increase on metal guest addition and the conversion rate between the closed and open isomers changed depending on the cation added. In particular, alkali metal cations decelerate the ring opening and closing while alkaline earth cations accelerate the process.

\section{Photoswitchable receptors based on chromenes}

Benzo and naphthopyran have general structures where a benzopyran or a naphthopyran ring is attached through a tetrahedral carbon to two groups that are not joined to form spiro heterocyclic ring like in the parent compounds spiropyrans and spirooxazines. The mechanism for the photochromism of these compounds is similar to that of the oxazines involving, upon UV irradiation, the opening of the pyran ring. The result is the formation of open metastable photoproducts, having the structure of $o$-quinone-allides which are the coloured due to the increased electronic delocalization. Photoproducts revert to the starting material either thermally or photochemically by irradiation with light at higher wavelengths (Scheme 17). ${ }^{43,44}$ 


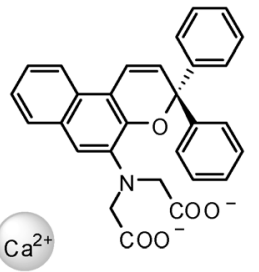

24a

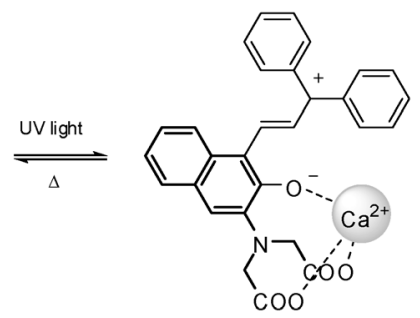

24b
Scheme $17 \mathrm{Ca}^{2+}$ uptake and release by photoisomerization of compound $\mathbf{2 4 a}$ to $\mathbf{2 4 b}$ and vice versa.

These molecules have found their main application as photochromic compounds for ophthalmic lenses. ${ }^{45}$

Chromenes' open forms are zwitterionic species where the anion is a phenolate. Such an electronically reach oxygen atom represents the starting point for tailoring a system that incorporates other functionalities capable of acting in synergy with the phenolate itself to bind an ionic guest. Since the phenolate is the result of the photoinduced process of ring opening of a chromene, the metal chelation by such a system should be fully reversible and controlled by light. An example of this concept was reported. ${ }^{46}$ Molecule 24a is a $3 H$-naphtho[2,1-b]pyran with an aminodiacetic acid substituent in the 5 position. The photoinduced ring opening by continuous UV irradiation generates the isomer $\mathbf{2 4 b}$ which exhibits higher affinity for $\mathrm{Ca}^{2+}$ than the closed form. The absorption maxima of the open form redshifted of $20 \mathrm{~nm}$ in the presence of calcium and a decrease of the thermal closure rate due to stabilization of the merocyanine coordinating the cation was observed. The cation release takes place when the irradiation ceases. Scheme 17 shows calcium uptake and release by the two isomers of compound $\mathbf{2 4}$.

A different mechanism of uptake/release of $\mathrm{Pb}^{2+}$ is involved in the photoinduced chelation by compound $25 .{ }^{47}$ The electron density of the crown ether ring fused to one of the two phenyl groups of its isomer 25a can be reduced by photoinduced ring opening by UV irradiation. The carbocation of the open form is consequently stabilized by electron donation from the crown ether. As a result, less electrons are available for coordinating $\mathrm{a}^{2+}$ cation. Thus, while 25a binds the guest in the cyclic ether, the photoinduced isomerization destabilizes the metal complex determining the metal liberation (Scheme 18).

The analogous effect of metal complex destabilization is achieved if the macrocyclic function is fused to benzopyran half of the molecular skeleton. ${ }^{48}$ In this example, the chelation of $\mathrm{Mg}^{2+}, \mathrm{Ba}^{2+}$, and $\mathrm{Pb}^{2+}$ by the two isomers $\mathbf{2 6} \mathbf{a}$ and $\mathbf{2 6} \mathbf{b}$ was

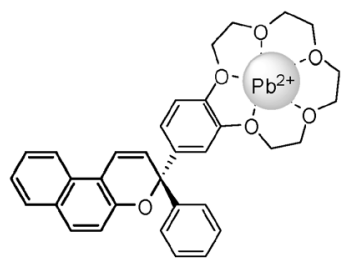

$25 \mathrm{a}$

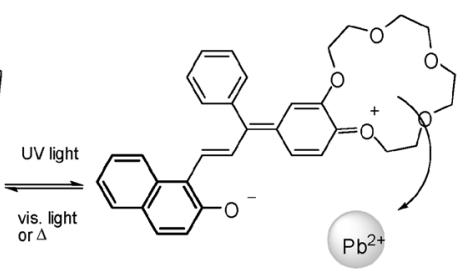

$25 b$
Scheme 18 Uptake and release of $\mathrm{Pb}^{2+}$ by the two isomers $25 \mathbf{a}$ and $25 \mathbf{b}$.
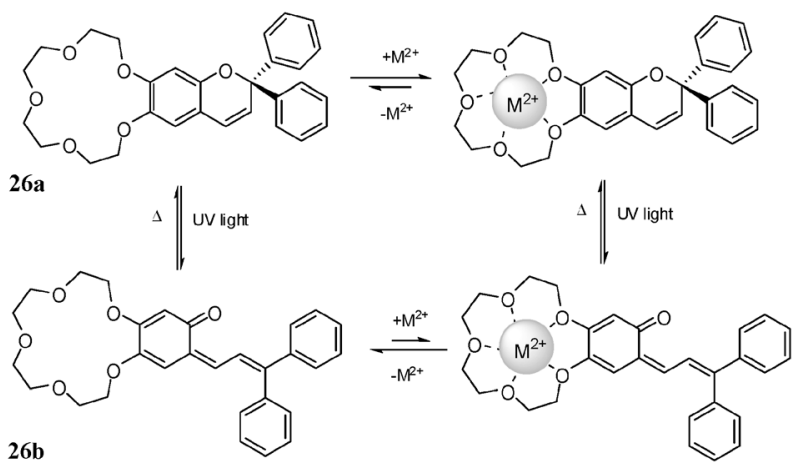

Scheme 19 Modulation of the uptake and release of a cation by photoconversion triggered by UV irradiation of chromene 26a to the corresponding merocyanine $\mathbf{2 6 b}$.

extensively studied. Metal chelation produced slight shifts of the closed form absorption maxima without triggering ring opening photoisomerization. Chromene-metal complexes with stoichiometry $1: 1$ and $2: 1$ were observed depending on the cation radius. Generally, smaller atoms tend to form $1: 1$ complexes while larger ones are coordinated by two crown ether moieties from two different molecules in a sandwich like fashion. Irradiation of acetonitrile solutions of ligand-free 26a resulted in the appearance of a new absorption band in the visible region which was attributed to the open photomerocyanine 26b. The latter reverts back to its closed form following a thermal path. Addition of metal ions to a chromene solution produced two significant effects on the ligand kinetic properties. The photomerocyanines appeared to have lower affinity for metal ions with respect to the corresponding closed isomers leading to partial destabilization of complexes. In parallel, complexation caused destabilization of the open forms resulting in a decrease of the coloured species lifetimes. Scheme 19 shows a representation of the equilibria involved in these processes.

A styryl fragment bearing crown ether ionophores was introduced on a photochromic chromene scaffold. The resulting molecules 27 and $\mathbf{2 8}$ are depicted in Scheme 20.

The styryl group offers a second photon-switchable chromophore that undergoes cis-trans isomerization upon UV irradiation. Both photochromic effects, cis-trans isomerization of the styryl unit and ring opening and closure of the chromene core driven by light were observed via UV-visible absorption spectroscopy. The inclusion of a $\mathrm{Mg}^{2+}$ cation in the ionophoric

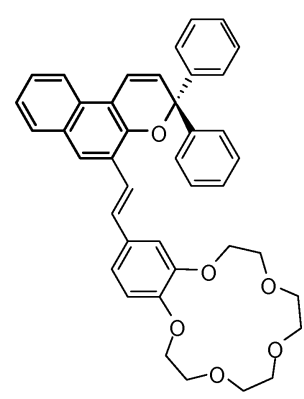

27

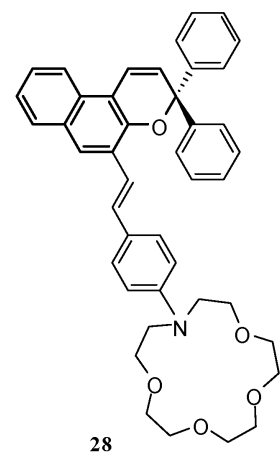

Scheme 20 Chromenes 27 and 28. 
cavities did not produce any change in the photoinduced response to UV and visible irradiation by the molecules. This is due to the fact that the rate constant of complexes formation is lower than the rate constant of their transformation to the open form. Additionally, the phenolate is too distant from the coordination site and this would not affect the chromene unit switchability.

\section{Photoswitchable receptors based on spirooxazines}

The term spirooxazine denotes a molecule containing an oxazine ring where the carbon in the 3-position is involved in a spiro linkage. The photoinduced cleavage of the bond between the spiro carbon and the oxazine oxygen produces a change valence-bond structure and conformation of the molecule. The resulting new species absorbs light at a different wavelength and, as a consequence, is coloured (Scheme 21). Firstly reported by Fox and Voynick, ${ }^{49}$ spirooxazines' photochromism in polymeric matrices is well established. ${ }^{50}$ Due to their capability to switch between the open and closed form both in solution and if included in polymers they have been considered perfect candidates for application in ophthalmology. Indeed, they were first used in Orgaver $^{\mathrm{TM}}$ sunglasses and in PHOTOLITE $^{\mathrm{TM}}$ photochromic lenses in the early 1980's. Current research on spirooxazine has investigated their photochromic behaviour for application in data storage processes and nonlinear optical phenomena. ${ }^{51}$

The chemical structures of spirooxazines are closely related to those of spiropyrans and chromenes as well as the mechanism of their photochromic reactions. In the same fashion of chromenes, heterocyclic cleavage of spirooxazines generates a metastable merocyanine. This species is a zwitterion whose negative charge is due to a phenolate anion site through which certain ( $\mathrm{d}$ - and f-element) metal ions can bind, giving rise to a new absorption band in the visible spectrum. ${ }^{52}$ A plausible mechanism for this chelation process is reported in Scheme 22 and shows the reversible chelation of a hypothetical bivalent cation by the two isomers $\mathbf{2 9}$ a and $\mathbf{2 9 b}{ }^{49}$ The azomethinic $\mathrm{N}$ and the phenoxide $\mathrm{O}$ may function as a bidentate chelator.

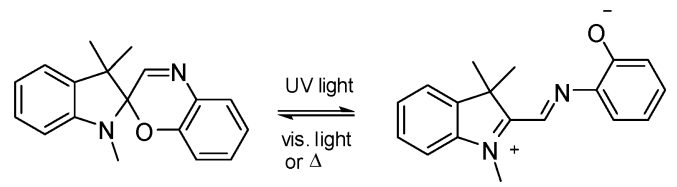

Scheme 21 Reversible photochromic conversion of a spirooxazine to its corresponding merocyanine by UV irradiation. The reverse cyclization is actuated by either visible light or thermal fading of the open form.

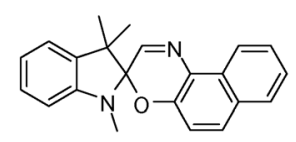

29a

$$
\mathrm{M}^{2+}
$$
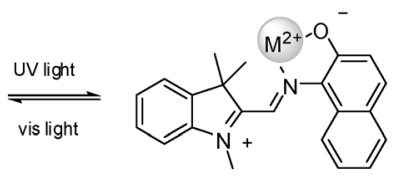

29b

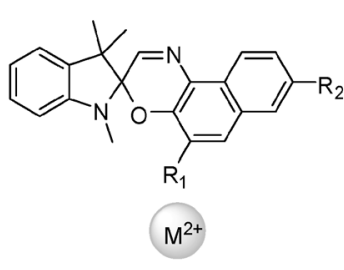

30a $\mathrm{R}_{1}=\mathrm{R}_{2}=\mathrm{SO}_{3}$

31a $\mathrm{R}_{1}=\mathrm{OMe}$ $\mathrm{R}_{2}=\mathrm{H}$

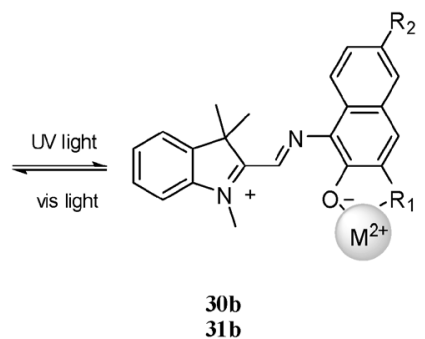

$31 \mathbf{b}$

Scheme 23 Isomerization of compounds 30a and 31a to their corresponding isomers $\mathbf{3 0 b}$ and $\mathbf{3 1 b}$ followed by chelation of bivalent cations $\mathrm{M}^{2+}=\mathrm{Cu}^{2+}, \mathrm{Ca}^{2+}$, or $\mathrm{Pb}^{2+}$.

More common strategies to produce a regenerable spirooxazine-based ligand are based on functionalization with suitable ionophoric groups. Generally, these additional coordinating groups are placed in a strategic position where they can easily interact with the phenolate and eventually cage a metal guest.

In the late eighties it was firstly reported that derivatives of spironaphthoxazine like 30a and 31a (Scheme 23), with a coordinating group near the $\mathrm{O}$ atom of the naphthoxazine moiety could be transformed into the coloured merocyanine on UV irradiation and subsequently chelate to certain bivalent metal ions. ${ }^{53,54}$ Aqueous solutions of 30a and 31a respond to UV light with the typical conversion to the open merocyanine 30b and 31b which revert back to the closed forms via either photochemical or thermal process. To generate complexes with $\mathrm{Cu}^{2+}, \mathrm{Ca}^{2+}$, and $\mathrm{Pb}^{2+}$, irradiation with $\mathrm{UV}$ light is necessary to produce the open forms. Thus, both the ester or methoxy groups and the phenolate anion can grab a cation together. The complex formation is detected as a slight blue shift of the open forms peak maxima and significant retardation of the thermal decolouration rate in the dark. Metal release can be achieved through irradiation with visible light. The presence of metals in the dark does not affect spirooxazines spectra.

Both photoinduced and spontaneous ionochromism were observed for $\mathbf{3 2}$ that bear a hydroxy group in the $5^{\prime}$-position of its naphthoxazine half (Scheme 24). ${ }^{55}$ Chelation of $\mathrm{Al}^{3+}$, $\mathrm{Fe}^{2+}$, or $\mathrm{Cu}^{2+}$ by the open photomerocyanine was achieved under steady irradiation of spiroindolinonaphthoxazines with UV light. This induces a slight hypsochromic shift of its visible absorption band and increases the lifetime of this form, slowing down its thermal bleaching in the dark. Complexation with the same metal cations allows the spiroindolinonaphthoxazine

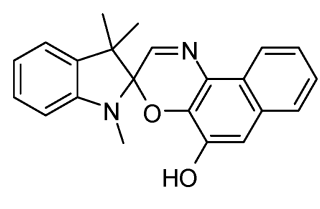

32

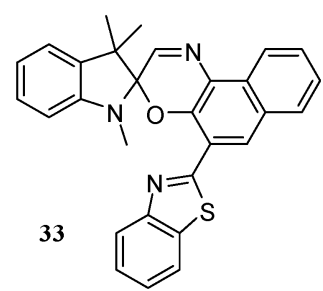

Scheme 24 Structures of photochromic and ionochromic spiroindolinonaphthoxazines $\mathbf{3 2}$ and $\mathbf{3 3}$.
Scheme 22 Representative metal ligation by a common spirooxazine via phenolate-imine bidentate chelator. 
to isomerize to its open coloured form even under dark conditions giving a complex spectroscopically identical to the photoinduced product. In the same manner, coordination of $\mathrm{Zn}^{2+}, \mathrm{Co}^{2+}$, or $\mathrm{Ni}^{2+}$ by compound 33, containing benzothiazolyl substituent in the naphthooxazine moiety as a potential chelating functional group (Scheme 24), was achieved via photostimulation with UV light that triggers the isomerization to the corresponding open merocyanine. Additionally this derivative responded to the presence of cations even under dark conditions giving a complex spectroscopically identical to the photoinduced product. As a result of the coordination, the thermal fading rate of the open form dramatically decreased with respect to that of a solution containing only the photochromic compound.

The synthesis and evaluation of the complexation ability of spirooxazines containing benzo-15(18)-crown-5(6) and aza-15crown-5 moieties in either $5^{\prime}$ or $9^{\prime}$ position (compounds 34-39, Scheme 25) have been reported. ${ }^{56-59}$ The two ionophores differ from each other because of their rigidity which is higher in the first case. This constrain plays an important role in the metal coordination of divalent cations. Indeed, compounds 34-36 can coordinate a metal cation relying only on the macrocyclic ether while the additional coordination by the phenolate oxygen of the open form does not take place. ${ }^{56,57}$ In contrast, compounds 37-39 containing an aza-15-crown-5 ionophore with a more flexible linker follows competitive routes in the coordination process. ${ }^{58,59}$ Comparative studies were performed on spectral properties of crown-ether-containing and crown-ether-free analogues and it was found that the phenolate anion of the open forms of compounds $\mathbf{3 8}$ and $\mathbf{3 9}$, bearing the heterocyclic moiety in position $9^{\prime}$, can coordinate both free metal cations and those already linked to an adjacent crown ether unit. A representation of this equilibrium between different metal complexes (in this case for compound 39) is depicted in Scheme 25.

The indolic nitrogen of a spirooxazine offers an additional site suitable for anchoring an ionophoric group. Thus the recognition site can rely on the synergy given by the phenolate of the open form. A series of spironaphthoxazines, $\mathbf{4 0 , 4 1}$, and 42 in Scheme 26, functionalized with a monoaza crown ether ring on the indolic nitrogen have been reported. ${ }^{60}$ These three compounds differ from each other because of their crown cavity size. They responded to the presence of alkali cations with the pyran ring opening and subsequent chelation of the cations. A comparative NMR study between these compounds and their spiropyran analogues bearing the same ionophores was carried out and it revealed that the affinity for metals of the spirooxazines is lower than that of spiropyrans. This is probably due to the fact that the open coloured forms of spironaphthoxazines are thought to exist also in their neutral keto forms, so that stabilization by an alkali-metal cation might not be essential.

The photochromic properties and ionochromism of two spironaphthoxaznes conjugated with aza-15(18)-crown-5(6)ether moieties at the $8^{\prime}$ position of naphthalene fragment were studied. ${ }^{61}$

Upon addition of $\mathrm{Li}^{+}$and alkaline earth metal cations to solutions of $\mathbf{4 3}$ and $\mathbf{4 4}$ (Scheme 27), blueshifts of the UV absorption bands of the closed forms and redshifts of the
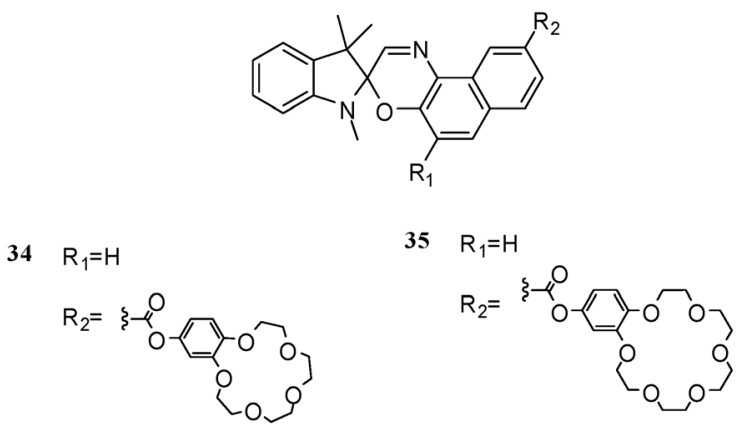

36

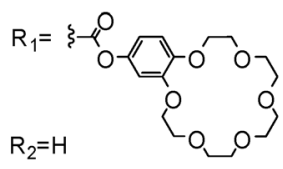

$37 \quad \mathrm{R}_{1}=\mathrm{H}$
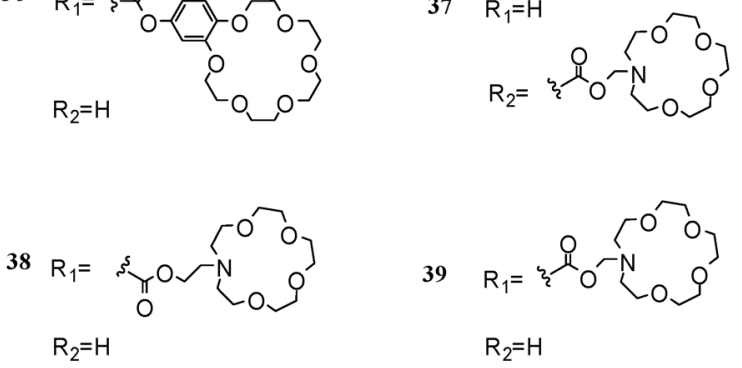

39
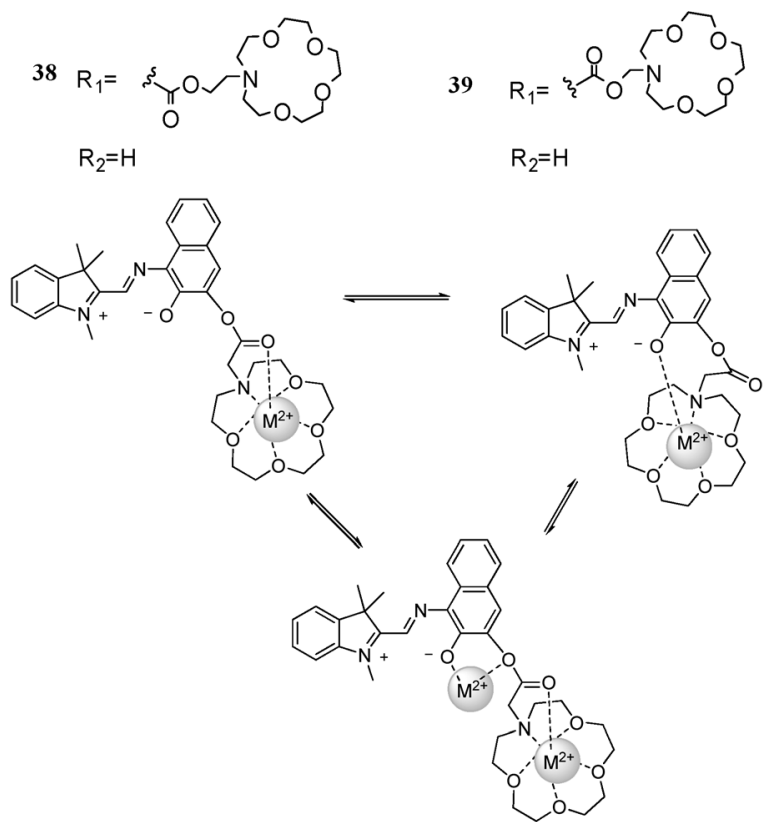

Scheme 25 Structures of photochromic crown-ether functionalized spirooxazine 34-39 and equilibrium between the hypothetical different complexes involved in the chelation by compound $\mathbf{3 8}$.

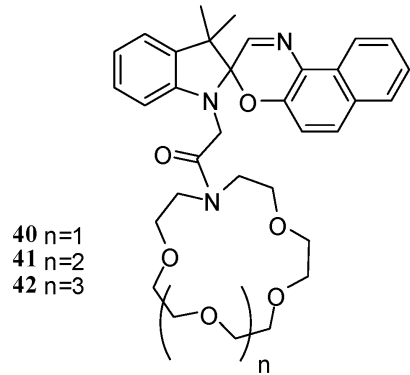

Scheme 26 Structures of photochromic spironaphthoxazines 40, 41, and $\mathbf{4 2}$ functionalized on the indolic part of the molecule with monoaza crown ether rings with different cavity sizes suitable for alkali metal cations recognition.

visible absorption bands of the open forms were observed. This is due to cation trapping in the crown ether cavity. The result of metal coordination is a dramatic increase of 


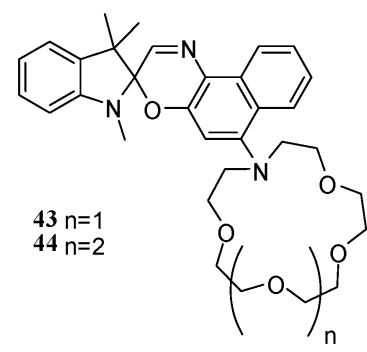

Scheme 27 Structures of photochromic spironaphthoxazines $\mathbf{4 3}$, and 44 functionalized with aza-15(18)-crown-5(6)-ether moieties at the $8^{\prime}$ position of the naphthalene fragment.

the open merocyanines lifetime. The photoinduced isomerization to their open form causes the decrease of the cation binding affinities.

\section{Photoswitchable receptors based on spiropyrans}

Nowadays, many different compounds have been shown to exhibit photochromism. Among them the class of spiropyrans has been probably the most extensively studied over the past several decades owing to the profitable applications they could be used for. Already in his early work Hirshberg envisaged the suitability of such compounds as photochemical erasable memory. ${ }^{62}$ Well-known photochromic compounds, spiropyrans or spirochromenes, are characterized by the presence of two heterocyclic parts linked to each other through a tetrahedral carbon atom. The two halves of the molecule are located on two perpendicular planes. The benzopyran moiety is a common motif present in most of the molecules. Absorption in the $200-400 \mathrm{~nm}$ range produces the cleavage of the bond that involves the spirocarbon and the oxygen atom generating a new zwitterionic species (Scheme 28). The latter, called merocyanine, undergoes a cis-trans isomerization of the double bond in the pyran ring to produce a more stable product. ${ }^{63-71}$ There is no disruption of the aromatic system and the absorption of the open form is dramatically redshifted to the visible region with respect to the closed spiropyran. The reversion to the closed form takes place either under thermal conditions or by a photochemical path. In the latter, visible light at a higher wavelength or continuous UV irradiation can be utilized. ${ }^{72}$

The closed and open isomers of a spiropyran are different chemical species that can undergo different reactions. This represents the basis for several applications in chemical sensing. Two reactive functions present in the coloured form but not in the colourless one are the phenolate anion and the positively charged indolium. The first has been the most exploited so far as its electron donating properties allow the interaction with

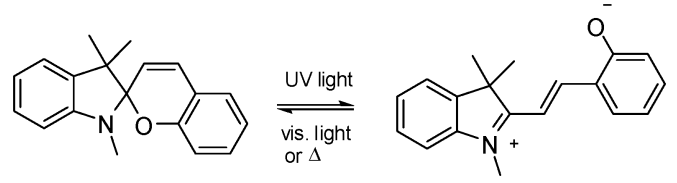

Scheme 28 Reversible photochromic conversion of a spiropyran to its corresponding merocyanine by UV irradiation. The reverse cyclization is actuated by either visible light or thermal fading of the open form.

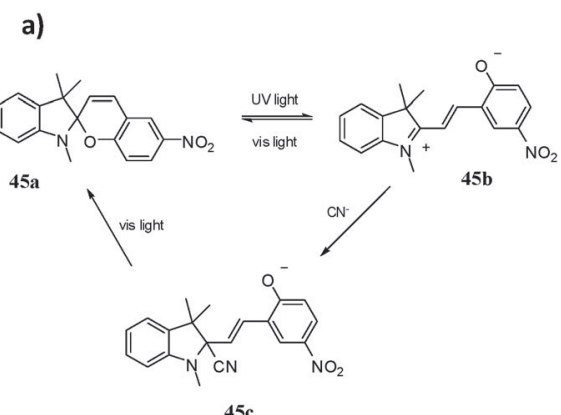

b)
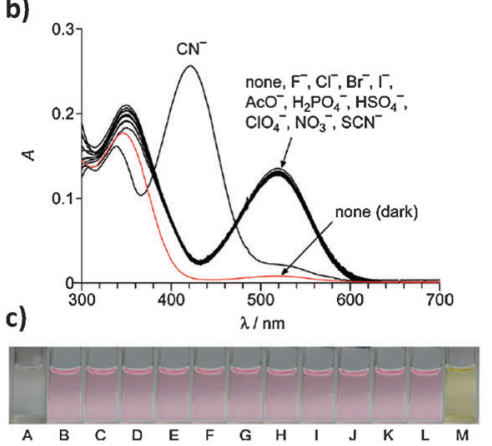

Fig. 4 (a) Structure changes of $45 a$ after irradiation with UV light (45b) and addition of $\mathrm{CN}^{-}$(45c); (b) absorption spectra of $1(20 \mu \mathrm{M})$ measured with 50 equiv. of respective anions (as a $n$ - $\mathrm{Bu}_{4} \mathrm{~N}^{+}$salt) in a water/MeCN mixture (1/1 v/v; CHES $100 \mathrm{mM}$, pH 9.3) under UV irradiation $(334 \mathrm{~nm})$ at $25^{\circ} \mathrm{C}$. The spectra were obtained after stirring the solution containing 1 and each anion for 30 min with UV irradiation. The red spectrum is obtained without anion in the dark; (c) photograph of the solutions (A) without anion (dark), (B) without anion, (C) $\mathrm{F}^{-}$, (D) $\mathrm{Cl}^{-}$, (E) $\mathrm{Br}^{-}$, (F) I' $\mathrm{I}^{-}$, (G) $\mathrm{AcO}^{-}$, (H) $\mathrm{H}_{2} \mathrm{PO}_{4}^{-}$, (I) $\mathrm{HSO}_{4}{ }^{-}$, (J) $\mathrm{ClO}_{4}^{-}$, (K) $\mathrm{NO}_{3}^{-}$, (L) $\mathrm{SCN}^{-}$, and (M) $\mathrm{CN}^{-}$. Adapted with permission from ref. 73. Copyright 2009 American Chemical Society.

electronically poor species like transition metal cations. However, the indolium ion of the merocyanine, produced by irradiation with UV light, has been reported to react selectively, sensitively, and reversibly with cyanide via nucleophilic addition (Fig. 4a). ${ }^{73-75}$ Compound 45a is an example. The formation of the spiropyran- $\mathrm{CN}^{-}$adduct $\mathbf{4 5 c}$ is detected in a water/acetonitrile solution, after UV irradiation of $\mathbf{4 5 a}$, as the solution turned from pink, which confirms the formation of the merocyanine $\mathbf{4 5 b}$, to yellow accompanied by the appearance of an intense absorption band in the visible region with maximum intensity at $421 \mathrm{~nm}$ (Fig. 4b and c). The cyanide detection is selective also in mixture with $\mathrm{F}^{-}, \mathrm{Cl}^{-}, \mathrm{Br}^{-}, \mathrm{I}^{-},[\mathrm{AcO}]^{-},\left[\mathrm{H}_{2} \mathrm{PO}_{4}\right]^{-}$, $\left[\mathrm{HSO}_{4}\right]^{-},\left[\mathrm{ClO}_{4}\right]^{-},\left[\mathrm{NO}_{3}\right]^{-}$, and $[\mathrm{SCN}]^{-}$and it is fully reversible if the solution containing the adduct is irradiated with visible light. The interaction of the same molecule with $[\mathrm{CN}]^{-}$and $\mathrm{F}^{-}$ anions in pure acetonitrile solutions has also been reported recently. In such a medium both anions undergo nucleophilic attack to the spiropyran but just the $[\mathrm{CN}]^{-}$containing species is stable upon UV irradiation while the $\mathrm{F}^{-}$adduct triggers the spiropyran degradation. $^{76}$

The coumarin-based spiropyran 46a (Fig. 5) is a structure developed recently and it is a selective sensor for cyanide. ${ }^{77}$ The mechanism of interaction with the anion is the same as for compound 45a but the presence of a coumarin half represents an improvement in its sensitivity. The presence of $[\mathrm{CN}]^{-}$in 


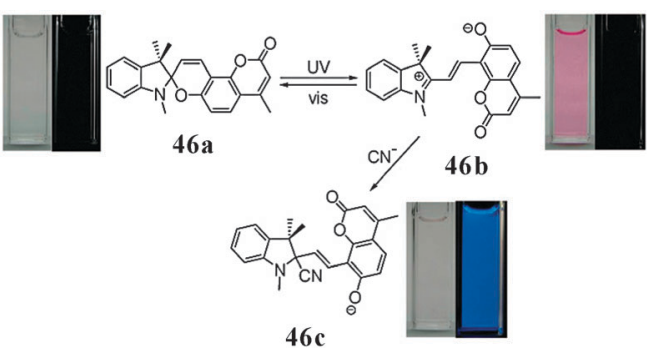

Fig. 5 Cyanide detection by isomerisation of compound 46a. Reproduced from ref. 77.
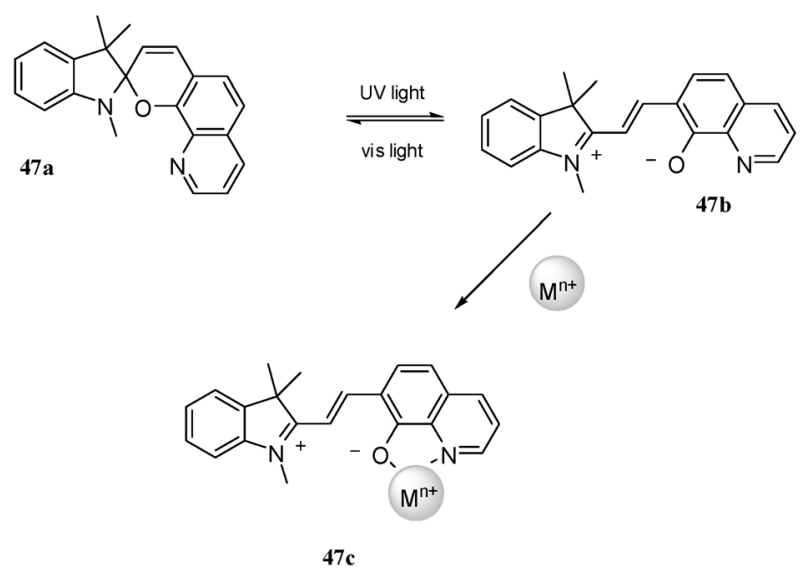

Scheme 29 Photochromism and chelation of $\mathrm{M}^{n+}=\mathrm{Fe}^{3+}$ or $\mathrm{Cu}^{2+}$ effected by the different isomers of compound $\mathbf{4 7}$.

aqueous solution containing 46a coupled with simultaneous UV irradiation produces the formation of the open form $\mathbf{4 6} \mathbf{b}$ followed by the formation of the adduct 46c. The latter is fluorescent owing to HOMO $\rightarrow$ LUMO transition of the $\pi$-electrons localized on the coumarin moiety. This event allows $[\mathrm{CN}]^{-}$titration via emission spectroscopy with a detection limit of $0.5 \mu \mathrm{M}$ which is a sharp improvement with respect to the value of $100 \mu \mathrm{M}$ obtained with $\mathbf{4 5 a}$.

As mentioned, the phenolate anion in conjunction with another appropriate group can give a chelating moiety. The synthesis and ionochromism of various quinolinospiropyranindolines have been extensively studied. The photoisomerization of such systems generates a reactive oxine function which can operate as a ligand for a multitude of metal cations. The first example was reported by Phillips and co-workers who noticed the deep red-purple coloration of a colourless solution of compound 47a, a few seconds after being irradiated with UV light and subsequent treatment with $\mathrm{Cu}^{2+}$ or $\mathrm{Fe}^{3+} .{ }^{78}$ These phenomena were explained as the result of metal coordination by the photochemically generated oxine $\mathbf{4 7 b}$ which exhibit its coordinating properties by forming the deeply coloured chelate $47 \mathrm{c}$ (Scheme 29).

The addition of a strong electron withdrawing group in the para position with respect to the benzopyran oxygen allows the delocalization of the electronic density of the phenolate anion. Thus the metal complexes are strongly destabilized and the metal can be ejected by photoisomerization to the closed form induced by visible light irradiation. Collins and collaborators reported their studies on zinc(II) release by the

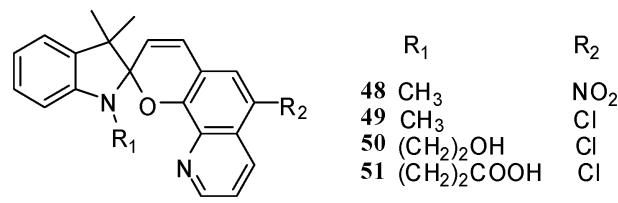

Scheme 30 Quinolinospiropyranindolines 48-51 bearing different substituents on the indolic nitrogen and the $6^{\prime}$ position of the quinolinospiropyran moiety.

open form of spiropyran $\mathbf{4 8}$ (Scheme 30), modified with a nitro group in the $6^{\prime}$ position, in an aqueous environment. ${ }^{79}$ They pointed out the fact that the cation release can be induced only if the molecule presents a strong electron withdrawing group opposite to the phenoxy oxygen.

Compounds 49-51 have the same skeleton as compound $\mathbf{4 7}$ but a chlorine as substituent in the $6^{\prime}$ position of the quinolinospiropyran half and different alkylic chains on the indolic nitrogen (Scheme 30). ${ }^{80}$ Their photochromic behaviour was investigated via $\mathrm{UV}$-vis spectroscopy and the most stable merocyanine was that generated from irradiation of $\mathbf{4 9}$ with UV light. On the other hand, compounds $\mathbf{5 0}$ and $\mathbf{5 1}$ responded to the presence of zinc(II) and copper(II) with the formation of more stable complexes than those formed by compound 49 . This is due to the presence of the $\mathrm{OH}$ group on $\mathbf{5 0}$ and the $\mathrm{COOH}$ group on $\mathbf{5 1}$ which offer additional binding sites for the metal coordination.

Chelation of $\mathrm{Mg}^{2+}, \mathrm{Zn}^{2+}, \mathrm{Ni}^{2+}, \mathrm{Cu}^{2+}, \mathrm{Hg}^{2+}$, and $\mathrm{Pd}^{2+}$ by spiropyrans 52-57 (Scheme 31) has been reported. ${ }^{81}$ The hydroxy group adjacent to the benzopyran oxygen is a common motif present in all compounds belonging to this series. Once the spiropyrans isomerise to their open form, the hydroxy group is accessible for coordination of a metal along with the vicinal phenolate. Different functional groups were

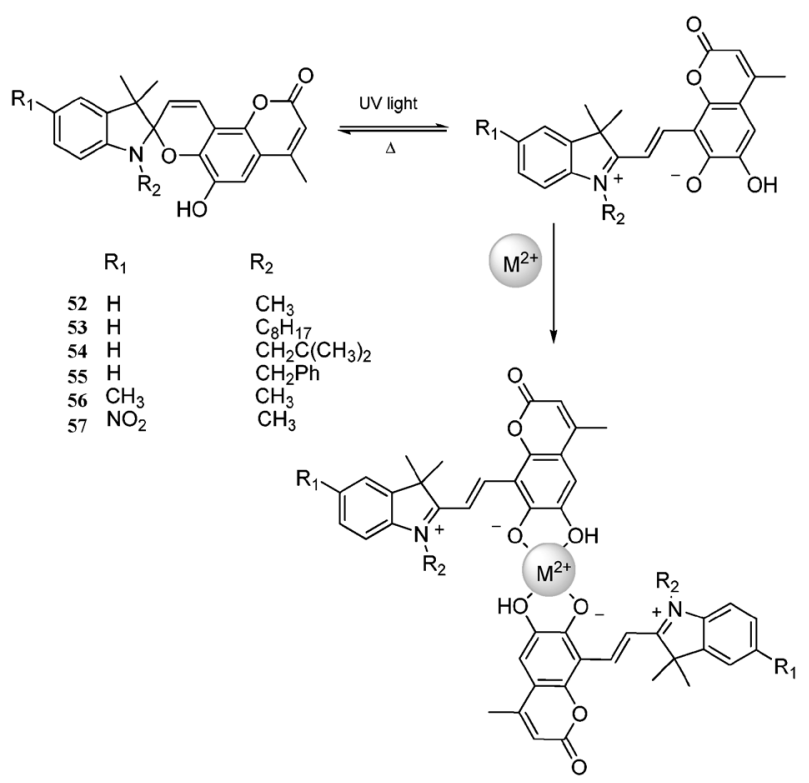

Scheme 31 Photoisomerization of spiropyrans 52-57 bearing different substituents on the indolic nitrogen and the 5 position of the indolic half followed by complexation of a metal cation $\mathrm{M}^{2+}=\mathrm{Mg}^{2+}, \mathrm{Zn}^{2+}$, $\mathrm{Ni}^{2+}, \mathrm{Cu}^{2+}, \mathrm{Hg}^{2+}$, and $\mathrm{Pd}^{2+}$. The complexes have a spiropyranmetal stoichiometry of $2: 1$. 


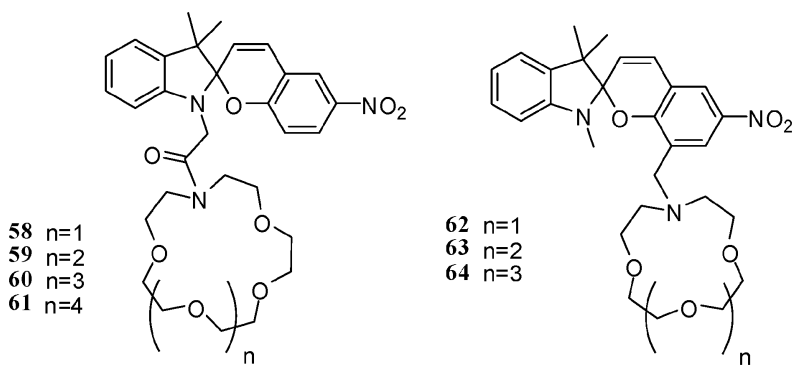

Scheme 32 Structures of photochromic spiropyrans 58-64 functionalized on the indolic part of the molecule with monoaza crown ether rings with different cavity sizes suitable for alkali metal cations recognition.

chosen for $R_{1}$ and $R_{2}$. A strong electron withdrawing group like $\mathrm{NO}_{2}$ in $\mathrm{R}_{1}$ (compound 57) dramatically reduced the merocyanine lifetime while an electron donating group (compound 56) stabilized the open form in a metal-free solution. The interactions of spiropyrans with metal cations were examined via UV-vis absorption and resulted in the appearance of intense absorption bands in the visible regions, blueshifted with respect to those of the free metal merocyanines. Additionally, all the complexes were found to have a spiropyranmetal stoichiometry of $2: 1$, which is plausible if two dyes in their open form cage the metal to form a tetradentate complex. The hypothetical structure of such a complex is depicted in Scheme 31.

A new class of host molecules, whose optical properties are markedly perturbed by the presence of cations, is that of crown-ring bearing spiropyrans. Inouye and his collaborators reported on the ionochromism of spiropyrans 58-61 functionalized with different size monoaza crown ethers to their indolic nitrogen (Scheme 32). ${ }^{82}$ The ionophoric group is suitable for interacting with alkali metal cations whose presence gave rise to strong absorption bands in the visible region, redshifted with respect to those of metal-free solutions of spiropyrans, which absorb in the UV region. The selective chelation of $\mathrm{Li}^{+}$ was observed for compounds $\mathbf{5 8}$ and $\mathbf{5 9}$, while $\mathbf{6 0}$ preferred $\mathrm{Na}^{+}$. No changes in the absorption spectrum of $\mathbf{6 1}$ were observed upon addition of any alkali-metal due to the large cavity of the monoaza crown ether appendix which impedes a proper interaction with the metal ion.

Analogously, spirobenzopyran derivatives having a monoazacrown moiety such as 12-crown-4 (62), 15-crown-5 (63) and 18-crown-6 (64) at the 8'-position have been reported (Scheme 32). ${ }^{83}$ Binding of alkali metal ions such as $\mathrm{Li}^{+}$, $\mathrm{Na}^{+}$, and $\mathrm{K}^{+}$by their crown rings leads to isomerization of spirobenzopyrans in the dark. NMR spectroscopy carried out on complexes containing the NMR active isotopes ${ }^{7} \mathrm{Li}$ and ${ }^{23} \mathrm{Na}$ suggested that cations, most significantly $\mathrm{Li}^{+}$, coordinated by the crown moiety in the merocyanine isomer are subject to intramolecular interactions with the merocyanine phenoxide anion. The additional-binding-site effect is eliminated on exposure to visible light as the cation-bound merocyanine readily reverts to its closed form, releasing the metal ions to some extent. Alternate irradiation with UV and visible light causes isomerization of the crowned spirobenzopyrans even in the presence of alkali metal ions, which in turn provides a tool for controlling their cation-complexing capability.
The synthesis and the alkaline-earth selective chelation by spiropyran based cryptands with a diazacrown ether bridge that connects the two halves of the spirochromene backbone were reported ${ }^{84}$ The crown ring cavity was varied in size. The addition of alkaline earth metal cation to acetonitrile solutions of compounds 65,66 , and 67 resulted in the appearance of broad absorption bands in the visible region with maxima depending on the metal coordinated by the cryptand. The isomerization of compound $\mathbf{6 6}$ stimulated by the presence of $\mathrm{Sr}^{2+}$ was investigated via ${ }^{1} \mathrm{H}-\mathrm{NMR}$ spectroscopy in acetonitrile. Fig. 5 shows the partial ${ }^{1} \mathrm{H}-\mathrm{NMR}$ spectra of $\mathbf{6 6}$ as a function of time, before and after the addition of $\mathrm{Sr}^{2+}$. The typical shifts of the closed form (Fig. 6a) underwent dramatic change after the addition of the metal (Fig. 6b) and reached a stable equilibrium after 3 hours from the addition (Fig. 6c).

A spiropyran based MRI (magnetic resonance imaging) contrast agent was described ${ }^{85}$ The molecule 68 is functionalized with an azacrown ether ring in the $8^{\prime}$-position of its benzopyran part (Scheme 33). The ionophore contains three carboxylated appendixes which can cage a $\mathrm{Gd}^{3+}$. At the ground state, the complex exists in the open merocyanine form with the gadolinium ion coordinated by the crown ether and the phenoxy group of the photochromic unit. Irradiation with visible light produced the spiropyran ring closure accompanied by a relaxivity decrease of $18 \%$ while UV light restored the open merocyanine and the normal relaxivity. Addition of NADH to the complex caused a drop of relaxivity of $26 \%$, but this time
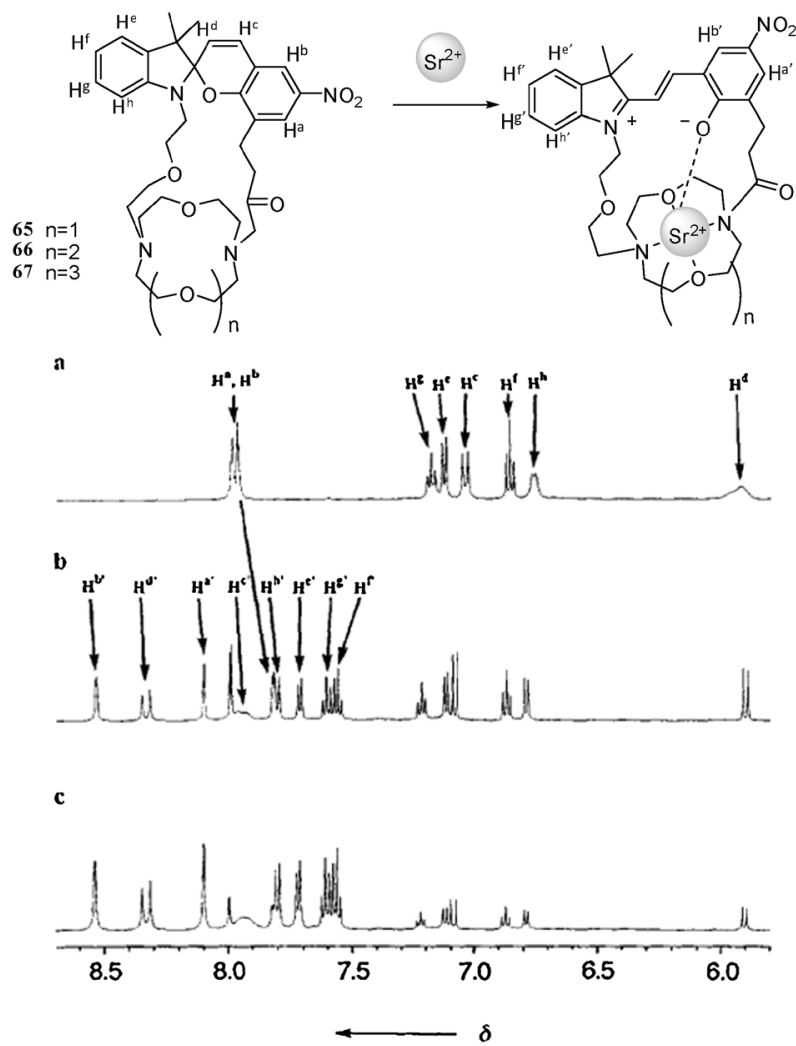

Fig. 6 Partial ${ }^{1} \mathrm{H}-\mathrm{NMR}$ spectra $(500 \mathrm{MHz})$ of 66 in $\mathrm{CD}_{3} \mathrm{CN}$ (a) before addition of $\mathrm{SrI}_{2}$, (b) $30 \mathrm{~min}$ after the addition, and (c) after $3 \mathrm{~h}$. Adapted with permission from ref. 84. Copyright Wiley-VCH Verlag GmbH \& Co. KGaA. 


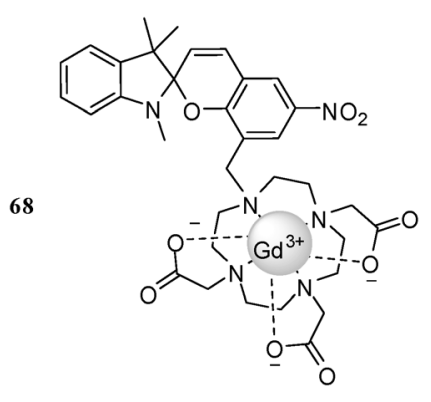

Scheme 33 Spiropyran based MRI contrast agent.

the event was irreversible. Such a unique response to NADH offers the possibility to investigate non-invasively metabolic activities and cell signalling in vivo.

The behaviour of crowned bis(spirobenzopyran) 69 (Scheme 34) was investigated in solution and compared with the corresponding derivative with only one photochromic unit. $^{86-88}$ The complexation of divalent and trivalent metal ions like $\mathrm{Ca}^{2+}$ and $\mathrm{La}^{3+}$ by the macrocyclic ionophore promotes isomerization of the spirobenzopyran units to their corresponding merocyanines. The resulting metal complex is stabilized by intramolecular interactions between the crowncomplexed cation and the two phenoxide anions. ${ }^{1} \mathrm{H}-\mathrm{NMR}$ spectroscopy was carried out on the lithium-merocyanine complex generated from 69. The results indicate that, upon complexation with $\mathrm{Li}^{+}$, one of the two spirobenzopyran units in compound 69 isomerizes to its open form. The complexation of divalent and trivalent metal cations by 69 forces the second unit to isomerise and complete the binding cage around the metal guest.

An interesting application of the reversible ionophoric properties of spiropyran 69 and its corresponding derivative 70 (Scheme 34) bearing a smaller crown ether bridge between the two spirochromene units was reported more recently by the same authors. The metal ion transport using liquid membranes was investigated. ${ }^{89}$ The transport was performed on a U-shaped glass cell with three distinctive phases: a source phase containing water solutions of alkali metals, an organic phase containing the crown ether modified spiropyrans and a receiving phase containing aqueous tetramethylammonium hydroxide. The transport of the alkali metal from the source phase to the receiving aqueous phase through the spiropyran liquid membrane was accelerated by UV-light irradiation and retarded under visible light exposure. When the visible light is on, the spiropyran units exist in their closed form and the

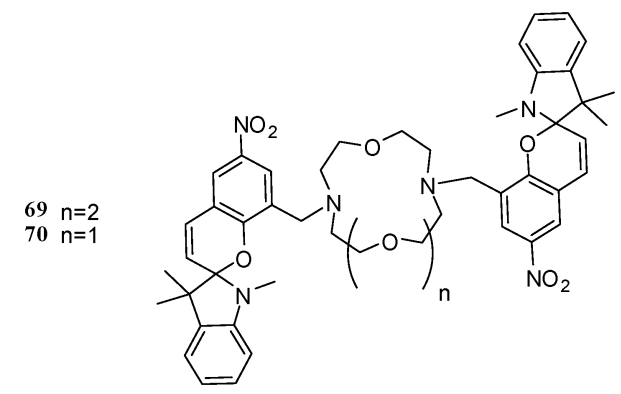

Scheme 34 Structures of photochromic bis(spiropyrans) 69 and 70 used in the metal cation active transport through a liquid membrane.

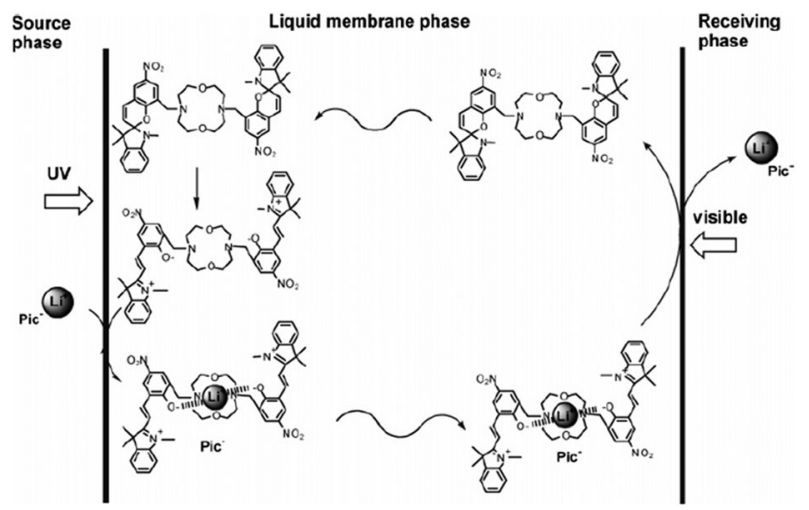

Fig. 7 Mechanisms at boundary phase between source, membrane and receiving phases for transport of $\mathrm{Li}^{+}$through the liquid membrane containing compound 70. Reproduced with permission from ref. 89. Copyright 2005 American Chemical Society.

interaction between the crown moiety and the metals is the only one likely to take place. Irradiation with UV light improves the interaction with the metal guests because of the additional binding sites on the open merocyanines. Thus the cation extraction from the source phase and the release in the receiving phase are largely accelerated. A schematic overview on the transport of lithium picrate through a liquid membrane containing compound 69 effected by sequential switching of UV-visible light is depicted in Fig. 7.

Bis(spiropyrans) containing azacrown fragments $\mathbf{7 1}$ and $\mathbf{7 2}$ and their corresponding derivative possessing one photochromic unity, 73 and 74, were reported (Scheme 35). ${ }^{90}$ They showed the capability to recognize transition metal cations like $\mathrm{Cu}^{2+}$,
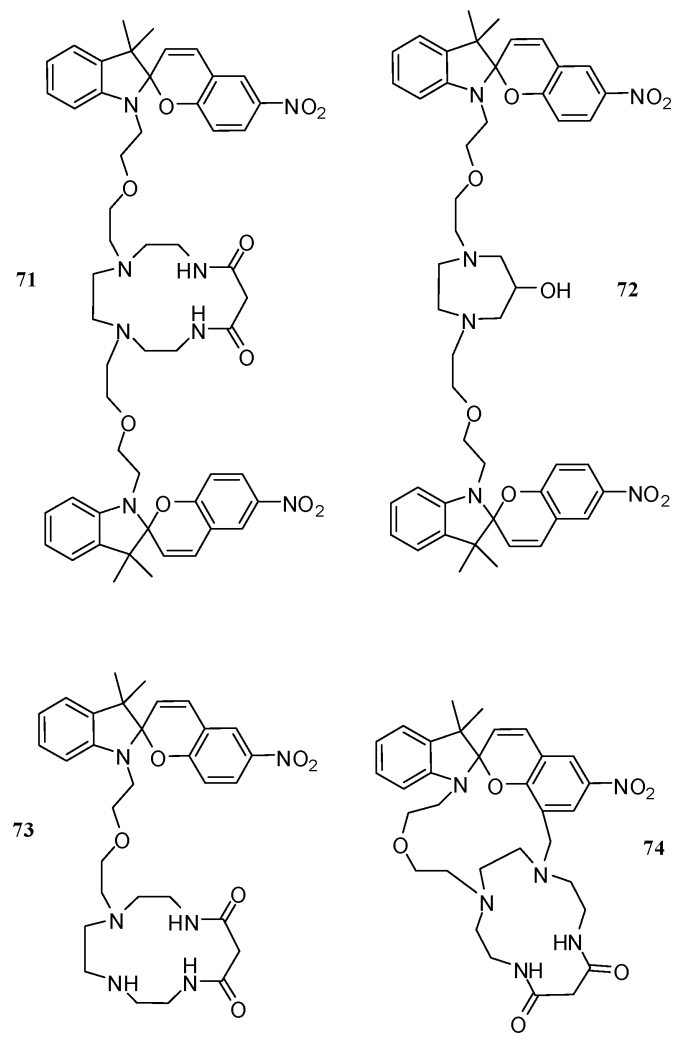

Scheme 35 Structures of photochromic bis(spiropyrans) 71-74. ${ }^{90}$ 


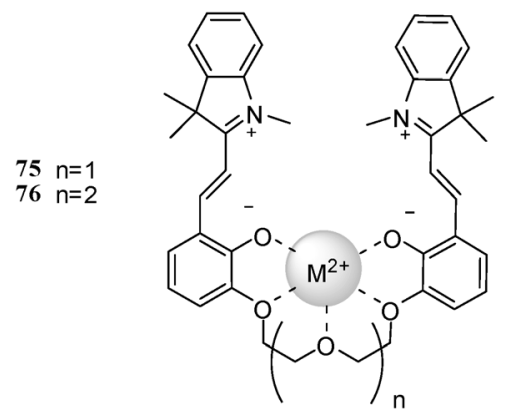

Scheme 36 Alkaline earth cations selective sensor synthesized by Yagi and co-workers. The picture shows the hypothetical structure of the complex with an alkaline-earth metal cation $\mathrm{M}^{2+}$.

$\mathrm{Co}^{2+}$, and $\mathrm{Ni}^{2+}$ owing to isomerization to their corresponding merocyanines. Selectivity for $\mathrm{Co}^{2+}$ was observed for all compounds while compound $\mathbf{7 3}$ responded selectively to $\mathrm{Cu}^{2+}$.

Another example of coordination of metal cations through the cooperation of two spiropyrans was provided. ${ }^{91}$ They synthesized a series of chemosensors selective for alkalineearth metal ions. Such molecules consist of two spiropyrans linked to each other through an oligoether chain attached in position $8^{\prime}$ of each photochrome. Compounds $\mathbf{7 5}$ and $\mathbf{7 6}$, Scheme 36, are two examples. They observed that the podands were able to selectively coordinate alkaline earth metal cations and the chelation involved both the merocyanine generated by the presence of the cation (Scheme 36). This was confirmed by ${ }^{1} \mathrm{H}-\mathrm{NMR}$ which showed signals consistent with the open form with no trace of the closed form. In addition the signals of the spacer were shifted indicating that it participated in the chelation. By modifying its length, a higher selectivity toward cations with larger radii is achievable. ${ }^{91}$

In a similar manner, the selective binding of calcium and magnesium was achieved by linking two spiropyran units via an alkylic tether attached to the indolic nitrogen of each photochrome. $^{92}$ Bis-benzospiropyranindoline 77 (Scheme 37) chelating ability was investigated and compared to simple mono-spiropyrans. Kinetic binding constants were measured and moderately strong metal binding occurs in acetone solution when the bis-spiropyran is irradiated at $365 \mathrm{~nm}$. This binding is eight times higher than the binding of the analogous mono-spiropyrans studied. The absorption maximum of the merocyanine form of the bis-spiropyran at $548 \mathrm{~nm}$ is strongly influenced by the metal. Absorbance maxima blue-shifts of $43 \mathrm{~nm}$ for $\mathrm{Mg}^{2+}$ and $22 \mathrm{~nm}$ for $\mathrm{Ca}^{2+}$ complexes were observed. Additionally, both metal complexes exhibited strong fluorescence with emission maxima at $586 \mathrm{~nm}\left(\lambda_{\mathrm{exc}}=365 \mathrm{~nm}\right)$ for magnesium and $606 \mathrm{~nm}$ for calcium.

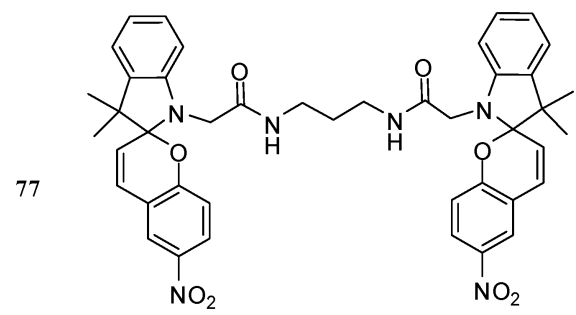

Scheme 37 Calcium and magnesium selective sensor 77 linking two spiropyran units via alkylic tether attached to the indolic nitrogen.
The selective coordinating of lanthanide ions of the calix[4]arene derivate $\mathbf{7 8 a}$ carrying two spirobenzopyran moieties are described by Liu and collaborators. ${ }^{93}$ The two photochromic units are attached to the lower rim of a calixarene system via alkylic linkers. In the ground state, an acetonitrile solution contains 78a and its corresponding isomer $\mathbf{7 8 b}$ with the photochromic units isomerized to open merocyanines. ${ }^{1} \mathrm{H}-\mathrm{NMR}$ analysis showed the equilibrium to be shifted toward $\mathbf{7 8 b}$, which absorbs in the visible region with a maximum at $555 \mathrm{~nm}$. Under dark conditions, addition of lanthanide ions resulted in significant hypsochromic shifts from 68 to $84 \mathrm{~nm}$ accompanied by a drastic intensity increase of absorption maxima in the visible region. In these events, the authors hypothesized that the lanthanides were entraped in the calixarene cavity followed by the metal coordination by the phenolic oxygen of the two open merocyanines. Thus the equilibrium between $\mathbf{7 8 a}$ and $\mathbf{7 8 b}$ is shifted toward a third new species $\mathbf{7 8 c}$ (Fig. 8a). Addition of alkali metal cations ( alkali earth metal cations (such as $\mathrm{Mg}^{2+}, \mathrm{Ca}^{2+}$ ) or transition metal cations (such as $\mathrm{Fe}^{3+}, \mathrm{Cu}^{2+}, \mathrm{Zn}^{2+}$ ) resulted in no visible changes in the UV-vis absorption spectra (Fig. 8b). Moreover, the lanthanide complexes exhibited strong fluorescence enhancement with respect to non-coordinated lanthanide cations in solution. The complexes fluorescence was quenched after irradiation with visible light that caused the open merocyanines to isomerise to their corresponding closed form.

A series of novel spiropyran functionalized to act as molecular receptors for a variety of hosts such as metal cations, amino acids and glutation was reported. These molecules possess outstanding properties despite the simplicity of their structures. The first example is spiropyran 79a functionalized with a dimethylamino methyl substituent in the $8^{\prime}$ position which forms a bidentate site with the phenolate oxygen of the
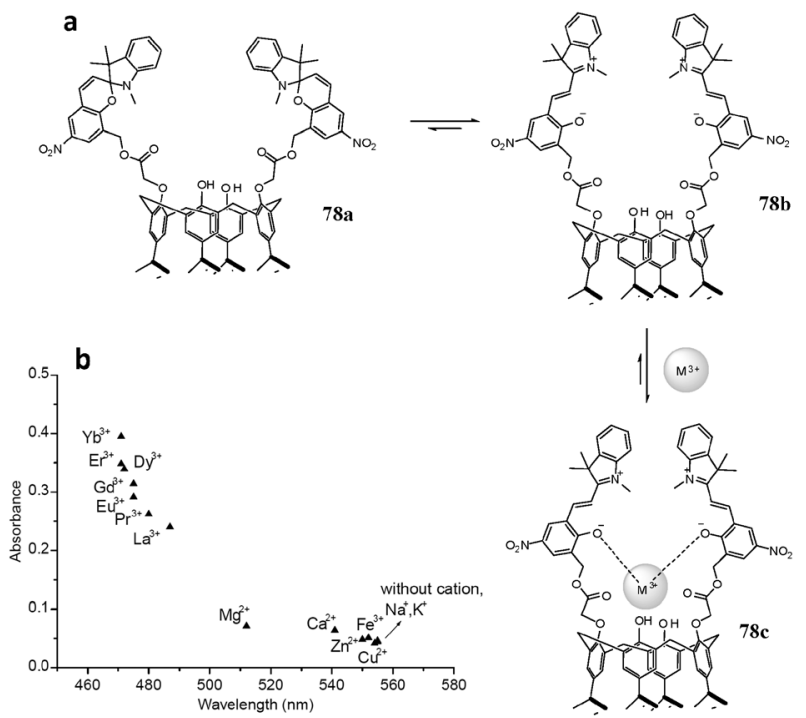

Fig. 8 (a) Sketches of equilibrium reactions of compound 78a and its corresponding isomers $\mathbf{7 8 b}$ and $\mathbf{7 8 c}$ in the presence of lanthanide ions $\mathrm{M}^{3+}$; (b) UV-vis spectra of $78 \mathbf{a}(40 \mathrm{mM})$ in the presence of and without metal ions $(20 \mathrm{mM})$ in acetonitrile under dark conditions for $48 \mathrm{~h}$. The selectivity toward lanthanides is obvious as the absorption maxima shift to shorter wavelengths and undergo dramatic intensity increases. Adapted from ref. 93. 

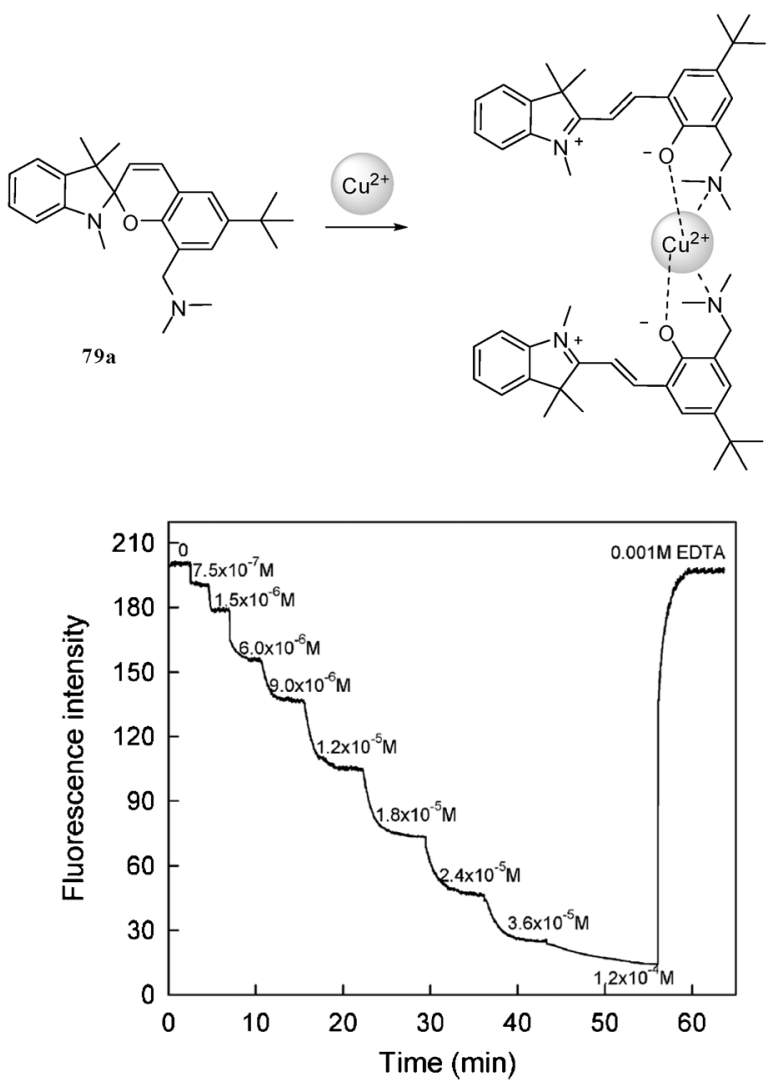

Fig. 9 Schematic representation of the isomerization of compound 79a to its open merocyanine 79b with chelation of $\mathrm{Cu}^{2+}$. The plot indicates time history of the sensing membrane responses to different concentrations of $\mathrm{Cu}^{2+}$. Fluorescence intensity was recorded at $603 \mathrm{~nm}\left(\lambda_{\mathrm{exc}}=556 \mathrm{~nm}\right)$. Adapted with permission from ref. 94. Copyright 2005 American Chemical Society.

open form 79b that coordinates selectively $\mathrm{Cu}^{2+}$ (Fig. 9). While a metal-free solution of 79a does not absorb in the visible region, the coordination of copper(II) was detected as the appearance of a broad absorption band with maximum at $547 \mathrm{~nm}$ (spiropyran/metal ratio $=2: 1$ ). The selective detection of copper(II) was performed by means of an inner filter effect approach. The spiropyran was immobilized in a poly-(vinyl chloride) membrane with a fluorescent zinc meso-tetraphenylporphyrin (Zntpp) fluorophore whose excitation band overlaps with the absorption band of $\mathbf{7 9 b}$. Thus, depending on the copper concentration, the porphyrin emission was quenched as the excitation light was competitively absorbed by the spiropyran-metal complex. The detection was fully reversible as the liberation of copper from the complex was achieved by addition of EDTA to the complexed solution. ${ }^{94}$ The plot in Fig. 9 shows the quenching of the membrane fluorescence after addition of increasing concentrations of $\mathrm{Cu}^{2+}$.

In the spiropyran derivative 80, a morpholine functionality was covalently attached at the $8^{\prime}$-position instead of the dimethylamino group present on 79a. ${ }^{95}$ A closely related structure bearing a piperidine in the $8^{\prime}$-position and a nitro group in the $6^{\prime}$-position was reported in 1967 by Taylor and co-workers. ${ }^{95}$ They noticed that colourless solutions in acetonealcohol containing their compound responded to the addition of $\mathrm{Co}(\mathrm{II}), \mathrm{Cu}(\mathrm{II})$, and $\mathrm{Zn}$ (II) with intense orange coloration.
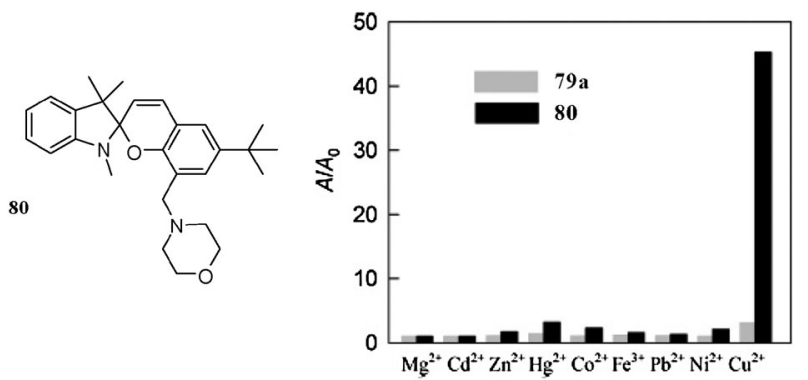

Fig. 10 The absorbance changes, $A / A_{0}$, of ethanol/water solutions $1: 1$ of 79a (gray, $540 \mathrm{~nm}$ ) and $\mathbf{8 0}$ (black, $453 \mathrm{~nm}$ ) upon addition of $5.0 \times 10^{-5} \mathrm{M}$ metal ions ( $x$-axis markers), separately. Adapted with permission from ref. 96. Copyright 2008 American Chemical Society.

They anticipated this phenomenon to be caused by the formation of merocyanine/metal complexes. The morpholine decorating $\mathbf{8 0}$ improved both water solubility and absorbance response to the presence of $\mathrm{Cu}^{2+}$ ions. Indeed, compound $\mathbf{8 0}$ displayed very high specificity for $\mathrm{Cu}^{2+}$ in an aqueous solution even in the presence of high concentrations of competitive heavy metal ions. Additionally, the direct detection of $\mathrm{Cu}^{2+}$ in human serum in the presence of heavy metals was successfully performed. Such a response was not observed with derivative 79a. ${ }^{96}$ Fig. 10 shows the photocolorability of the derivatives 79a and 80 toward various metal ions defined as the absorption changes $\left(A / A_{0}\right)$ at the wavelength of maximum absorption of spiropyran-metal complexes. Here $A_{0}$ and $A$ are the absorbance of the photochromes in the absence of and the presence of a cation. The selectivity for $\mathrm{Cu}^{2+}$ of $\mathbf{8 0}$ is evident.

In a different study, the same authors proposed a new method that allows simple and efficient recognition and quantification of cysteine (Cys) and homocysteine (Hcy) by spiropyran derivative 79a. ${ }^{97}$ The detection mechanism was proven by IR and ${ }^{1} \mathrm{H}-\mathrm{NMR}$ techniques and it involves the cooperative ligation of either $\mathrm{Cu}^{2+}$ or $\mathrm{Hg}^{2+}$, two merocyanines 79b and two amino acids linked to each other via a disulfide bridge. The Cys and Hcy recognition was successful in aqueous media, at physiologic $\mathrm{pH}$ and it was selective over a series of different amino acids. Fig. 11 displays the mechanism proposed
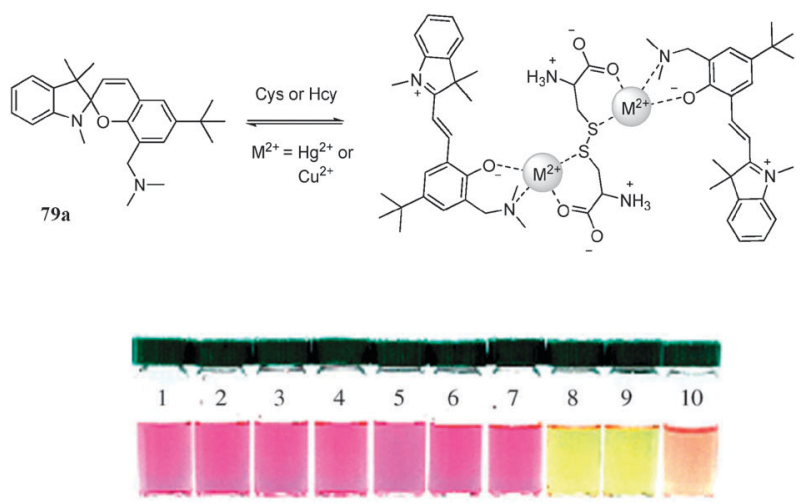

Fig. 11 Color changes of an ethanol/water solution containing 79a and $\mathrm{Hg}^{2+}$ in the presence of different amino acids: (1) no amino acid, (2) Gly, (3) Leu, (4) His, (5) Glu, (6) Asp, (7) Met, (8) Cys, (9) Hcy, and (10) GSH (glutathione). Adapted with permission from ref. 97. Copyright Wiley-VCH Verlag GmbH \& Co. KGaA. 

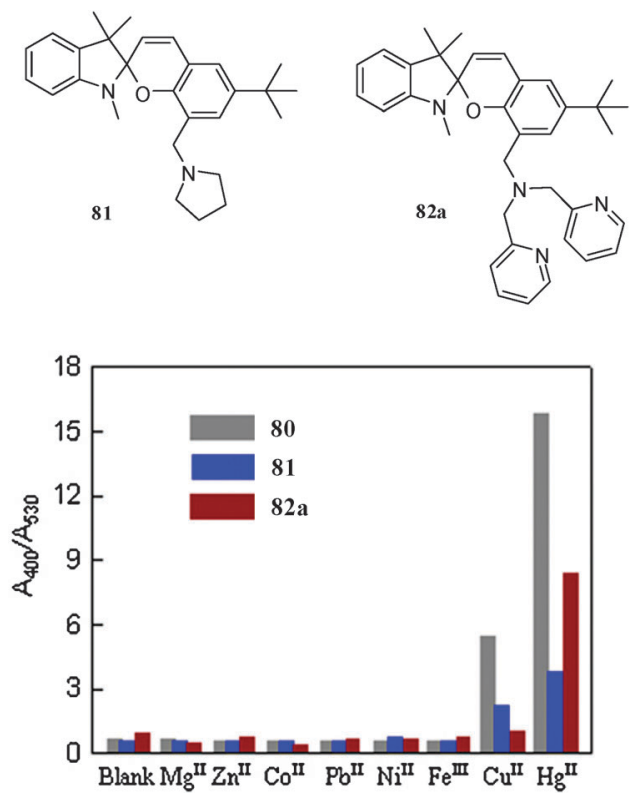

Fig. 12 The absorbance ratio changes $A_{400} / A_{530}$, of 80, 81, and 82a in the ethanol-water solution upon additions of selected metal ions in the presence of Cys. Adapted from ref. 98.

by Shao for the cooperative ligation of the photochromic compound, Cys or Hcy, and either a copper or a mercury cation.

The same approach of integrating a spiropyran molecule and an amino acid cooperatively to a metal center could be used for optical sensing of $\mathrm{Hg}^{2+}$ ions in aqueous solution. The new spiropyran derivatives $\mathbf{8 1}$ and 82a (Fig. 12) have been developed and their binding ability was tested on $\mathrm{Mg}^{2+}$, $\mathrm{Ca}^{2+}, \mathrm{Mn}^{2+}, \mathrm{Pb}^{2+}, \mathrm{Fe}^{3+}, \mathrm{Co}^{2+}, \mathrm{Ni}^{2+}, \mathrm{Zn}^{2+}$, and $\mathrm{Hg}^{2+}$ and compared with compound $\mathbf{8 0}$.

Considering the response sensitivity and the detection range in aqueous solutions containing $5 \%$ of ethanol, experimental conditions were optimized and the relative amount of Cys and spiropyran was set at $5: 1$. The histogram in Fig. 12 shows the sensors response to the metal cations as the ratio between two wavelengths, $530 \mathrm{~nm}$ and $400 \mathrm{~nm}$, where the absorptions are notable for all spiropyrans. Interference was observed for the chelation of $\mathrm{Hg}^{2+}$ and $\mathrm{Cu}^{2+}$ by $\mathbf{8 0}$ and $\mathbf{8 1}$ while compound 82a was selective for mercury. ${ }^{98}$

The Dpa substituent on 82a is known for its capability to form a complex with $\mathrm{Zn}^{2+}$ (82b in Fig. 13) in aqueous solutions. The authors found that the coordination between the two species encourages the ligation of a pyrophosphate anion (PPi) selectively (structure 82c). ${ }^{99}$ This phenomenon was studied extensively and the interaction mechanism was explained as the result of the coordination of a pyrophosphate by two spirochromene-zinc units (Fig. 13). The presence of $\mathrm{PPi}$ in an aqueous solution containing the 82c complex was detected as a fluorescence intensity decrease at $630 \mathrm{~nm}$ concomitant to an increase at $530 \mathrm{~nm}$. The fluorescent ratiometry plot in Fig. 13 shows the changes in the fluorescence intensity of $\mathbf{8 2}$ at $560 \mathrm{~nm}$ with respect to that at $620 \mathrm{~nm}$ in the presence of the different anion Pi, PPi, ADP, ATP, citrate, tartrate, succinate, and oxalate and the selectivity for PPi is obvious. Additionally, the PPi concentration in human urine was successfully determined.

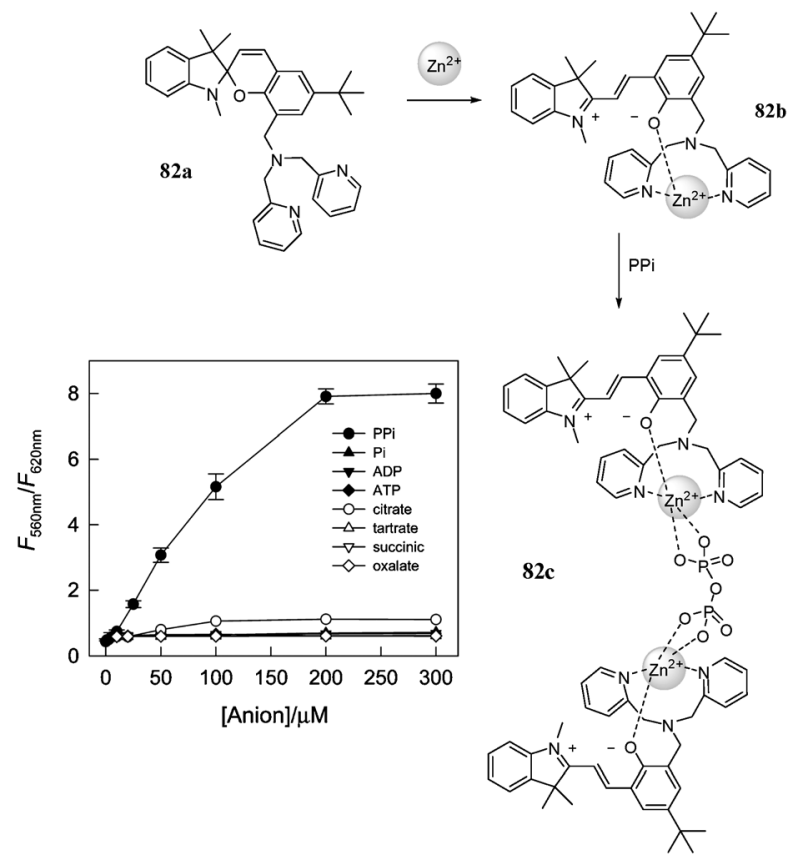

Fig. 13 Mechanism of the chelation of zinc followed by the coordination of a pyrophosphate anion. The plot shows the changes in the fluorescence intensity of 82a at $560 \mathrm{~nm}$ with respect to that at $620 \mathrm{~nm}$ in the ethanol aqueous solution $(\mathrm{pH} 7.4)$ upon addition of different concentrations of anions $\left(\lambda_{\text {exc }}=522 \mathrm{~nm}\right)$. The values of $F_{560 \mathrm{~nm}} / F_{620 \mathrm{~nm}}$ underwent an increase only in the presence of PPi proving the selectivity toward this anion. ${ }^{99}$ Adapted with permission from ref. 99. Copyright 2010 American Chemical Society.

Two novel bis(spiropyrans) $\mathbf{8 3}$ and $\mathbf{8 4}$, incorporating two photochromes tethered to each other via either a piperazine or a binol linker, were synthesized aiming for the detection of glutathione in living cells. ${ }^{100}$ They represent an example of an organic sensor with remarkable properties for in vivo applications. For both sensors, the molecular recognition is based on multipoint electrostatic interactions and structure complementarity between the open merocyanine forms and a glutathione molecule (Fig. 14). Surprisingly, the presence of thiolated amino acids or other peptides did not interfere with the GSH interaction which indeed showed strong fluorescence emission. Confocal fluorescence microscopy experiments were carried out for compound $\mathbf{8 4}$ with human acute $\mathrm{T}$ cells leukaemia. The spiropyran was internalized in the cells and produces fluorescence enhancement by GSH complexation.

Spiropyrans bearing carboxylated chains on the indolic nitrogen are known to be good binding agents as well as those functionalized with a methoxy group on the benzopyran moiety. ${ }^{95,101-103}$ We recently reported spiropyran $\mathbf{8 5}$, functionalized with a carboxylated tether on the indolic nitrogen and a methoxy group on the benzopyran moiety. ${ }^{104}$ This compound reversibly bind $\mathrm{Cu}(\mathrm{II})$ and $\mathrm{Zn}$ (II) cations giving rise to different optical responses depending on the counter ion. Indeed compound $\mathbf{8 5}$ is particularly sensitive to $\mathrm{Zn}$ (II) in solution which causes the formation of fluorescent SP-Zn complexes even if the cation is present in low concentrations. Both cations are fully released upon irradiation with visible light. The emission spectra of compound $\mathbf{8 5}$ before and after the addition of $\mathrm{Zn}$ (II) are shown in Fig. 15. 


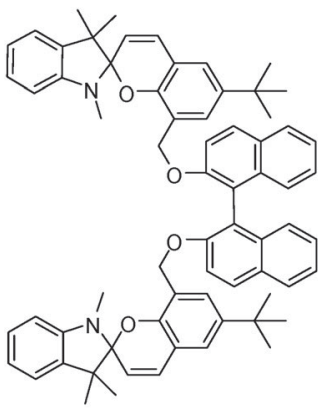

83
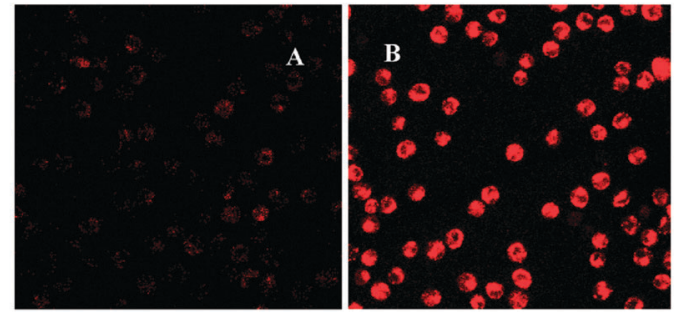

Fig. 14 Confocal microscope images of human acute T-cell leukaemia (A) without spiropyran, (B) incubated with $100 \mu \mathrm{M} 84$ for $3 \mathrm{~h}$. The fluorescence visible in (B) is given by the formation of a complex between $\mathbf{8 4}$ and glutathione. Adapted with permission from ref. 100. Copyright 2010 American Chemical Society.

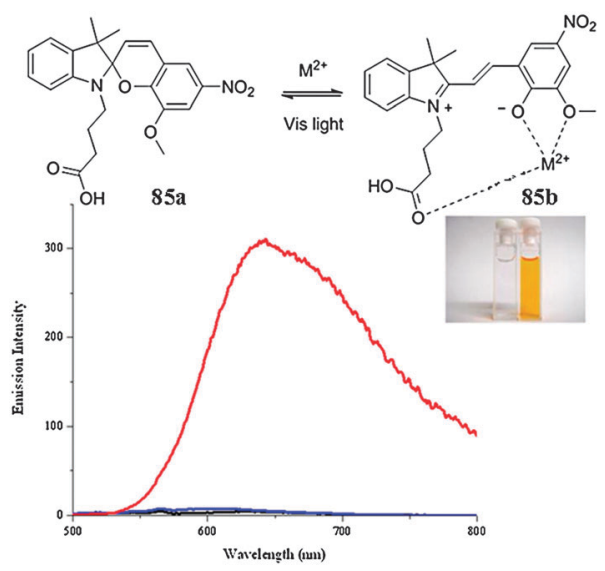

Fig. 15 Emission spectra of an $\mathbf{8 5}$ solution $\left(1.0 \times 10^{-5} \mathrm{M}\right.$, acetonitrile, $293 \mathrm{~K}$ ) before (black), after the addition of 1 equivalent of $\mathrm{ZnCl}_{2}$ (red) and after the subsequent irradiation with visible light (blue); (picture) coloration of an 85a solution $\left(1.0 \times 10^{-5} \mathrm{M}\right.$, acetonitrile, $\left.293 \mathrm{~K}\right)$ after addition of $\mathrm{ZnCl}_{2}$. Adapted from ref. 104 .

We also synthesized the novel spiropyran 86a which differs from 85 by the presence of a methyl pyridinyl group on the indolic nitrogen. ${ }^{105}$ This structural difference affords a more rigid molecule that is selectively and reversibly capable of chelating $\mathrm{Zn}$ (II) also in a mixture with other cations. The presence of zinc causes the formation of the coloured complex 86b that absorbs light in the visible region. Additionally, even if slight interference was observed in the presence of $\mathrm{Cu}(\mathrm{II})$, the $\mathrm{SP}-\mathrm{Zn}$ complex is the only one showing emissive behaviour. The release of $\mathrm{Zn}$ (II) is effected by shining visible light on the SP-Zn solution. This operation could be repeated several times without any efficiency loss as shown in Fig. 16.

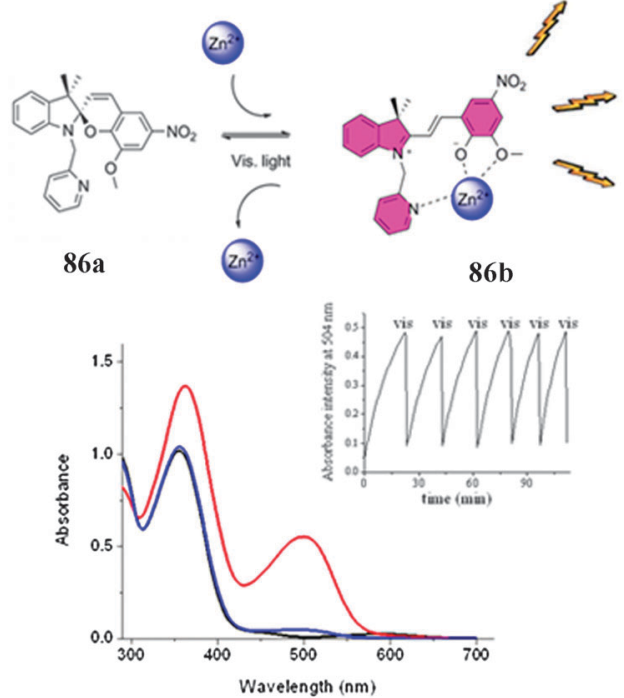

Fig. 16 Absorption spectra of $\mathbf{8 6}\left(1.0 \times 10^{-4} \mathrm{M}\right.$, acetonitrile, $\left.293 \mathrm{~K}\right)$ before (black), after the addition of 1 equiv. of $\mathrm{Zn}\left(\mathrm{ClO}_{4}\right)_{2}$ (red) and after the subsequent irradiation with visible light (blue); (inset) sequential cycles of conversion between $\mathbf{8 6} \mathbf{a}$ and $\mathbf{8 6} \mathbf{b}$ controlled by visible light. Adapted from ref. 105.
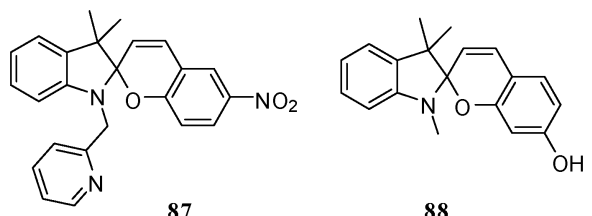

Scheme 38 Spiropyrans reported by Ren (87) and Han (88).

We recently reported the effect of $\mathrm{Cu}$ (II) on four spiropyran derivatives, causing the dimerization of the molecules. ${ }^{106}$

Two noteworthy examples of selective spiropyran-based ion sensors were reported by Ren ${ }^{107}$ and Han. ${ }^{108}$ Ren's molecule, compound 87, resembles compound $\mathbf{8 6}$ a bearing a pyridinil residue as an active binding site. No functional groups are present on the benzopyran half of its skeleton. This structural features yielded Ren's spiropyran highly selective towards $\mathrm{Al}(\mathrm{III})$ cations. Irradiation with $\mathrm{UV}$ light in the presence of the metal in $\mathrm{MeCN} / \mathrm{H}_{2} \mathrm{O}$ solution causes the molecular switch to open to its merocyanine form which can bind the cation through a phenoxy-pyridine bidentate system. The latter is deeply yellow coloured. Compound $\mathbf{8 7}$ showed selectivity for $\mathrm{Al}^{3+}$ over $\mathrm{Li}^{+}, \mathrm{Na}^{+}, \mathrm{K}^{+}, \mathrm{Mg}^{2+}, \mathrm{Ca}^{2+}, \mathrm{Cu}^{2+}, \mathrm{Ba}^{2+}, \mathrm{Fe}^{2+}$, $\mathrm{Hg}^{2+}, \mathrm{Cd}^{2+}, \mathrm{Cr}^{2+}, \mathrm{Pb}^{2+}, \mathrm{Co}^{2+}, \mathrm{Ni}^{2+}, \mathrm{Cs}^{+}, \mathrm{Ag}^{+}, \mathrm{NH}^{4+}$ and $\mathrm{Sn}^{2+}$. Han's spiropyran possess only an $\mathrm{OH}$ group in the $7^{\prime}$-position. Despite its simple molecular structure, compound 88 showed selectivity toward $\mathrm{Hg}^{2+}$ in solution detected by the formation of a pink $\mathrm{SP}-\mathrm{Hg}$ complex. However, this interaction is a one-way process as irradiation with visible light does not lead to metal release but to photodegradation of $\mathbf{8 8}$. The selective interaction with mercury was observed over $\mathrm{Ca}^{2+}, \mathrm{Mg}^{2+}, \mathrm{Zn}^{2+}, \mathrm{Cd}^{2+}, \mathrm{Co}^{2+}, \mathrm{Cu}^{2+}, \mathrm{Mn}^{2+}, \mathrm{Fe}^{2+}$, $\mathrm{Ni}^{2+}, \mathrm{Pb}^{2+}, \mathrm{K}^{+}, \mathrm{Na}^{+}, \mathrm{Li}^{+}$, and $\mathrm{Ag}^{+}$. Spiropyrans 87 and $\mathbf{8 8}$ are shown in Scheme 38.

The first spiropyran based selective receptor for nucleosides was reported by Inouye and co-workers in the early nineties. ${ }^{109}$ 


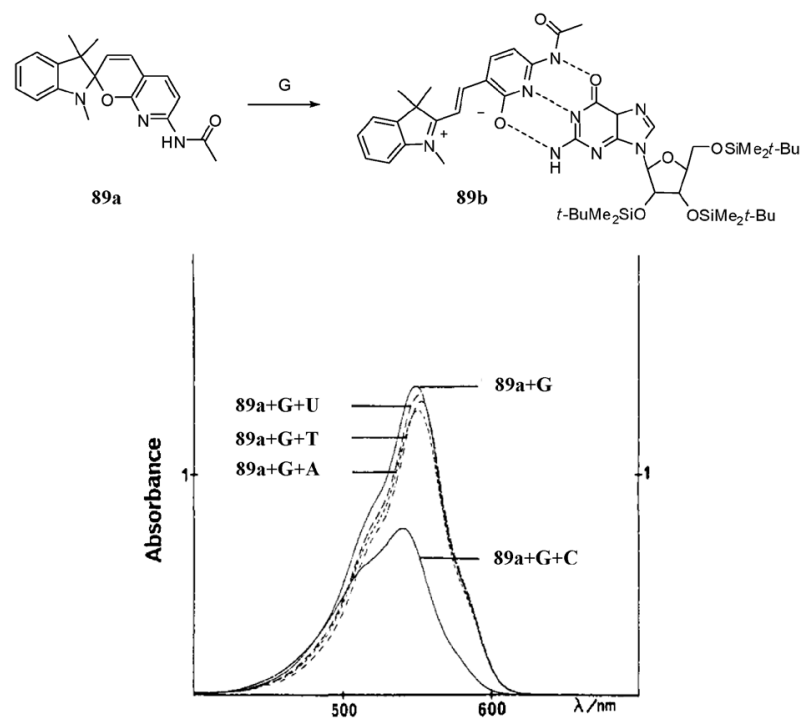

Fig. 17 Coordination mechanism of $\mathbf{8 9} \mathbf{a}$ with a guanosine $\mathbf{G}$ derivative to the complex 89b. Absorption spectra of a solution containing 89a and $\mathbf{G}$ in the absence and in the presence of other nucleosides cytidine (C), uridine (U), thymidine (T), and adenosine (A). Adapted with permission from ref. 109. Copyright 1992 American Chemical Society.

Compound 89a can selectively bind a guanosine relying on the triple hydrogen bond formation between the acetamidopyridone anion unit of its open form and the complementarity of the nucleoside structure (structure 89b in Fig. 17). This interaction produced dramatic changes in the UV-vis absorption spectrum of 89a with the appearance of a strong absorption band with maximum intensity at $550 \mathrm{~nm}$. Despite the small interference with cystidine, the selectivity was not affected by the presence of other nucleosides (plot in Fig. 17). Later, the same authors reported on the synthesis and activity evaluation of the ferrocene-modified bis(spiropyridopyran) 90a, aimed at the selective recognition of guanine-guanine (GG) dinucleoside derivatives. ${ }^{110}$ They demonstrated the high selectivity of the receptor by means of ${ }^{1} \mathrm{H}-\mathrm{NMR}$ and UV-vis absorption spectroscopy. In particular, upon addition of GG or G, a solution of 90a turned red and an intense absorption band appeared in the visible region with maximum intensity at $575 \mathrm{~nm}$. No significant changes in the absorption spectra were observed in the presence of other

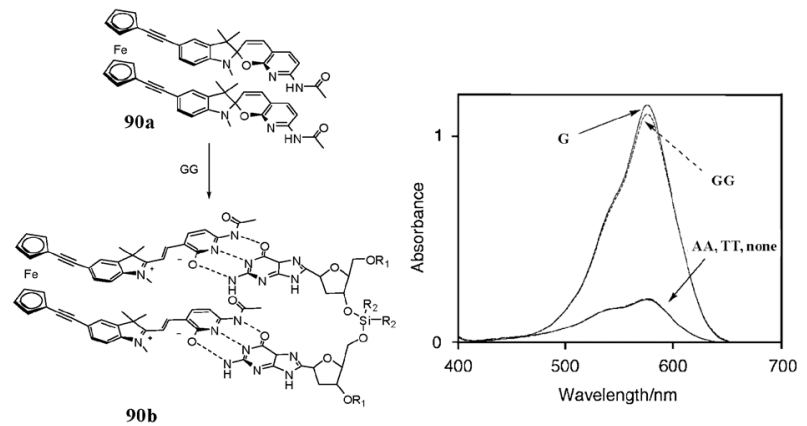

Fig. 18 Electronic absorption spectra of $90 \mathrm{a}\left(3.0 \times 10^{-2} \mathrm{mM}\right)$ in the presence of the lipophilic nucleosides guanosine $(\mathbf{G})$, guanosine-guanosine (GG), thymidine-thymidine (TT), and adenosine-adenosine (AA) derivatives $\left(3.0 \times 10^{-2} \mathrm{mM}\right)$ in $\mathrm{CH}_{2} \mathrm{Cl}_{2}$ at $25^{\circ} \mathrm{C}$. Adapted from ref. 110 . nucleosides (absorption spectra in Fig. 18). The authors suggested that the inter-ring spacing of the two ferrocene rings is close to the spacing between the stacked base pairs and its restricted conformational flexibility allows the merocyanine units to interact with the complementary guanine-guanine modules. The proposed mechanism of interaction is depicted in Fig. 18.

\section{Conclusions}

Herein we have summarised the use of photochromic compounds as versatile sensors for ions and biologically important molecules. We have demonstrated how different strategies may be used in order to tailor their molecular skeleton in order to obtain the structural capability to recognise a chemical guest and retaining switchability. These strategies include:

- the simple conjugation to common substrate recognition moieties such as crown ethers and calixarenes, specifically designed for cations, and boronic acids for sugars;

- conjugation with non-specific functional groups such as carboxylated tethers, amino groups, pyridyl and Dpa substituents, etc.;

- synthesis of photoswitchable dimers that are capable to function as chelators.

The host-guest interaction can be either spontaneous or stimulated by irradiation with light of an appropriate wavelength, and the resulting complex can be easily detected as its optical properties differ from the unbound precursor. In the same way, light can affect and disrupt the interaction between the molecular switch and substrate by either triggering structural modifications or forcing electronic density re-distribution in the photochrome skeleton.

Additionally, we have described that it is possible to incorporate in one single molecule not only switchability and recognition capability but also high selectivity for a single substrate. This approach may lead to new levels of molecular sensing, with receptors that can bind selectively and reversibly a multitude of chemical guests and thus overcoming the problem of a one-time use sensor.

We believe that the field of molecular sensing applied to molecular switches will continue to blossom and other related structures, such as the ultrafast oxazine-based molecular switches reported by Raymo et al. ${ }^{111,112}$ will also be employed for such sensing, either in conjunction with a specific binding unit or as independent entities themselves. Indeed, even more complex constructs like the multi-responsive molecular switch developed by Diederich et al. ${ }^{113}$ which incorporates a $\mathrm{pH}$ sensitive $N, N$ dimethylaniline, a cis-trans photoswitchable tetraethynylethene core, and a dihydroazulene photoresponsive unit could be a suitable platform for developing multitask sensors.

\section{Acknowledgements}

This work was supported by Science Foundation Ireland (PIYRA 07/YI2/I1052).

\section{Notes and references}

1 Y. Hirshberg and E. Fischer, J. Chem. Phys., 1955, 23, 1723-1723.

2 R. C. P. Bertelson, ed. G. H. Brown, Wiley, New York, 1971.

3 A. E. J. Wilson, Phys. Technol., 1984, 15, 232-238. 
4 R. P. M. a. S. Guglielmetti, in Photochromism: Molecules and Systems, ed. H. Durr and H. Bouas-Laurent, Elsevier, Amsterdam, 1990.

5 G. M. Tsivgoulis and J. M. Lehn, Angew. Chem., Int. Ed. Engl., 1995, 34, 1119-1122.

6 B. L. M. S. Feringa, Molecular Switches, Wiley-VHC, 2001.

7 G. M. Wyman, Chem. Rev., 1955, 55, 625-657.

8 H. Rau, Angew. Chem., Int. Ed. Engl., 1973, 12, 224-235.

9 K. Ishihara, N. Hamada, S. Kato and I. Shinohara, J. Polym. Sci., Part A: Polym. Chem., 1984, 22, 121-128.

10 K. Ishihara, N. Hamada, S. Kato and I. Shinohara, J. Polym. Sci., Part A: Polym. Chem., 1983, 21, 1551-1555.

11 M. Irie, Y. Hirano, S. Hashimoto and K. Hayashi, Macromolecules, 1981, 14, 262-267.

12 A. Mamada, T. Tanaka, D. Kungwatchakun and M. Irie, Macromolecules, 1990, 23, 1517-1519.

13 S. Shinkai, K. Shigematsu, M. Sato and O. Manabe, J. Chem. Soc., Perkin Trans. 1, 1982, 2735-2739.

14 H. Y. An, J. S. Bradshaw, R. M. Izatt and Z. M. Yan, Chem. Rev., 1994, 94, 939-991.

15 G. W. Gokel, W. M. Leevy and M. E. Weber, Chem. Rev., 2004, 104, 2723-2750.

16 S. Akabori, Y. Miura, N. Yotsumoto, K. Uchida, M. Kitano and Y. Habata, J. Chem. Soc., Perkin Trans. 1, 1995, 2589-2594.

17 S. Shinkai, T. Nakaji, Y. Nishida, T. Ogawa and O. Manabe, J. Am. Chem. Soc., 1980, 102, 5860-5865.

18 B. Pipoosananakaton, M. Sukwattanasinitt, N. Jaiboon, N. Chaichit and T. Tuntulani, Tetrahedron Lett., 2000, 41, 9095-9100.

19 Y. Yokoyama, Chem. Rev., 2000, 100, 1717-1739.

20 Y. Atassi, J. Chauvin, J. Delaire, J. F. Delouis, I. Fanton-maltey and K. Nakatani, Mol. Cryst. Liq. Cryst. Sci. Technol., Sect. A, 1998, 315, 11-22.

21 F. Matsui, H. Taniguchi, Y. Yokoyama, K. Sugiyama and Y. Kurita, Chem. Lett., 1994, 1869-1872.

22 L. H. Yu, Y. F. Ming, M. G. Fan, H. T. Yu and Q. Q. Ye, Sci. China Ser. E: Chem., 1996, 39, 1-6.

23 Y. Yokoyama, T. Ohmori and T. Okuyama, Mol. Cryst. Liq. Cryst., 2000, 344, 265-270.

24 Z. Guo, G. Wang, Y. Tang and X. Song, Liebigs Ann., 1997, 1997, 941-942.

25 R. M. Kellogg, M. B. Groen and H. Wynberg, J. Org. Chem., 1967, 32, 3093-3100.

26 M. Irie and M. Mohri, J. Org. Chem., 1988, 53, 803-808.

27 M. Takeshita, C. F. Soong and M. Irie, Tetrahedron Lett., 1998, 39, 7717-7720.

28 M. Takeshita and M. Irie, Tetrahedron Lett., 1998, 39, 613-616.

29 M. Takeshita and M. Irie, J. Org. Chem., 1998, 63, 6643-6649.

30 S. H. Kawai, Tetrahedron Lett., 1998, 39, 4445-4448.

31 H. Y. Hu, M. Z. Zhu, X. M. Meng, Z. P. Zhang, K. Wei and Q. X. Guo, J. Photochem. Photobiol., A, 2007, 189, 307-313.

32 J. P. Malval, I. Gosse, J. P. Morand and R. Lapouyade, J. Am. Chem. Soc., 2002, 124, 904-905.

33 Z. G. Zhou, S. Z. Xiao, J. Xu, Z. Q. Liu, M. Shi, F. Y. Li, T. Yi and C. H. Huang, Org. Lett., 2006, 8, 3911-3914.

34 M. Takeshita, K. Uchida and M. Irie, Chem. Commun., 1996, 1807-1808.

35 G. Hauck and H. Durr, Angew. Chem., Int. Ed. Engl., 1979, 18, 945-946.

36 R. Fromm, S. A. Ahmed, T. Hartmann, V. Huch, A. A. Abdel-Wahab and H. Durr, Eur. J. Org. Chem., 2001, 4077-4080.

37 Y. S. Tan, S. A. Ahmed, H. Durr, V. Huch and A. Abdel-Wahab, Chem. Commun., 2001, 1246-1247.

38 Y. P. Neo, A. Ariffin, C. P. Tan and Y. A. Tan, Int. J. Food Sci. Technol., 2008, 43, 1832-1837.

39 E. Gogritchiani, T. Hartmann, B. S. Palm, S. Samsoniya and H. Durr, J. Photochem. Photobiol., B, 2002, 67, 18-22.

40 H. Durr, A. Thome, C. Kranz, H. Kilburg, S. Bossmann, B. Braun, K. P. Janzen and E. Blasius, J. Phys. Org. Chem., 1992, 5, 689-698.

41 H. Durr and C. Kranz, Mol. Cryst. Liq. Cryst. Sci. Technol., Sect. A, 1994, 246, 135-138.

42 H. Durr, C. Kranz and H. Kilburg, Mol. Cryst. Liq. Cryst. Sci. Technol., Sect. A, 1997, 297, 365-372.

43 Y. A. Tan, L. N. Xing, Y. J. Gu and X. L. Zhang, N. Z.. J. Agric. Res., 2007, 50, 1021-1029.
44 Y. A. Tan, R. Sambanthamurthi, K. Sundram and M. B. Wahid, Eur. J. Lipid Sci. Technol., 2007, 109, 380-393.

45 J. C. Crano, T. Flood, D. Knowles, A. Kumar and B. VanGemert, Pure Appl. Chem., 1996, 68, 1395-1398.

46 S. Kumar, D. Hernandez, B. Hoa, Y. Lee, J. S. Yang and A. McCurdy, Org. Lett., 2008, 10, 3761-3764.

47 M. T. Stauffer, D. B. Knowles, C. Brennan, L. Funderburk, F. T. Lin and S. G. Weber, Chem. Commun., 1997, 287-288.

48 S. Paramonov, S. Delbaere, O. Fedorova, Y. Fedorov, V. Lokshin, A. Samat and G. Vermeersch, J. Photochem. Photobiol., A, 2010, 209, 111-120.

49 M. A. Fox and T. A. Voynick, J. Org. Chem., 1981, 46, 1235-1239.

50 G. Such, R. A. Evans, L. H. Yee and T. P. Davis, J. Macromol. Sci., Polym. Rev., 2003, C43, 547-579.

51 G. Berkovic, V. Krongauz and V. Weiss, Chem. Rev., 2000, 100, 1741-1753.

52 M. J. Preigh, F. T. Lin, K. Z. Ismail and S. G. Weber, J. Chem. Soc., Chem. Commun., 1995, 2091-2092.

53 T. Tamaki and K. Ichimura, J. Chem. Soc., Chem. Commun., 1989, 1477-1479.

54 J. W. Zhou, F. Q. Zhao, Y. T. Li, F. S. Zhang and X. Q. Song, J. Photochem. Photobiol., A, 1995, 92, 193-199.

55 S. Minkovska, M. Fedieva, B. Jeliazkova and T. Deligeorgiev, Polyhedron, 2004, 23, 3147-3153.

56 M. Elmaloulibibout, P. Lareginie, L. Noussi, A. Samat and R. Guglielmetti, Mol. Cryst. Liq. Cryst. Sci. Technol., Sect. A, 1994, 246, 177-181.

57 V. B. Nazarov, V. A. Soldatenkova, M. V. Alfimov, P. Lareginie, A. Samat and R. Guglielmetti, Russ. Chem. Bull., 1996, 45, 2105-2108.

58 O. A. Fedorova, S. P. Gromov, Y. P. Strokach, Y. V. Pershina, S. A. Sergeev, V. A. Barachevskii, G. Pepe, A. Samat, R. Guglielmetti and M. A. Alfimov, Russ. Chem. Bull., 1999, 48, 1950-1959.

59 O. A. Fedorova, S. P. Gromov, Y. V. Pershina, S. S. Sergeev, Y. P. Strokach, V. A. Barachevsky, M. V. Alfimov, G. Pepe, A. Samat and R. Guglielmetti, J. Chem. Soc., Perkin Trans. 2, 2000, 563-570.

60 M. Inouye, M. Ueno, K. Tsuchiya, N. Nakayama, T. Konishi and T. Kitao, J. Org. Chem., 1992, 57, 5377-5383.

61 O. A. Fedorova, Y. P. Strokach, S. P. Gromov, A. V. Koshkin, T. M. Valova, M. V. Alfimov, A. V. Feofanov, I. S. Alaverdian, V. A. Lokshin, A. Samat, R. Guglielmetti, R. B. Girling, J. N. Moore and R. E. Hester, New J. Chem., 2002, 26, 1137-1145.

62 Y. Hirshberg, J. Am. Chem. Soc., 1956, 78, 2304-2312.

63 F. M. Raymo and S. Giordani, Org. Lett., 2001, 3, 3475-3478.

64 F. M. Raymo and S. Giordani, J. Am. Chem. Soc., 2001, 123, 4651-4652.

65 F. M. Raymo and S. Giordani, Org. Lett., 2001, 3, 1833-1836.

66 F. M. Raymo and S. Giordani, J. Am. Chem. Soc., 2002, 124, 2004-2007.

67 F. M. Raymo and S. Giordani, Proc. Natl. Acad. Sci. U. S. A., 2002, 99, 4941-4944.

68 F. M. Raymo, S. Giordani, A. J. P. White and D. J. Williams, J. Org. Chem., 2003, 68, 4158-4169.

69 F. M. Raymo, R. J. Alvarado, S. Giordani and M. A. Cejas, J. Am. Chem. Soc., 2003, 125, 2361-2364.

70 S. Giordani, M. A. Cejas and F. M. Raymo, Tetrahedron, 2004, 60, 10973-10981.

71 C. B. Aakeroy, E. P. Hurley, J. Desper, M. Natali, A. Douglawi and S. Giordani, CrystEngComm, 2010, 12, 1027-1033.

72 V. Pimienta, D. Lavabre, G. Levy, A. Samat, R. Guglielmetti and J. C. Micheau, J. Phys. Chem., 1996, 100, 4485-4490.

73 Y. Shiraishi, K. Adachi, M. Itoh and T. Hirai, Org. Lett., 2009, 11, 3482-3485.

74 Y. Shiraishi, M. Itoh and T. Hirai, Tetrahedron, 2011, 67, 891-897.

75 Y. Shiraishi, M. Itoh and T. Hirai, Tetrahedron Lett., 2011, 52, $1515-1519$

76 Y. A. Tan, A. Kuntom, C. K. Lee and K. S. Low, J. Am. Oil Chem. Soc., 2004, 81, 733-736.

77 Y. Shiraishi, S. Sumiya and T. Hirai, Chem. Commun., 2011, 47, 4953-4955. 
78 J. P. Phillips, A. Mueller and F. Przystal, J. Am. Chem. Soc., 1965, 87, 4020.

79 G. E. Collins, L. S. Choi, K. J. Ewing, V. Michelet, C. M. Bowen and J. D. Winkler, Chem. Commun., 1999, 321-322.

80 A. V. Chernyshev, A. V. Metelitsa, E. B. Gaeva, N. A. Voloshin, G. S. Borodkin and V. I. Minkin, J. Phys. Org. Chem., 2007, 20, 908-916.

81 O. G. Nikolaeva, A. V. Tsukanov, E. N. Shepelenko, B. S. Lukyanov, A. V. Metelitsa, O. Y. Kostyrina, A. D. Dubonosov, V. A. Bren and V. I. Minkin, Int. J. Photoenergy, 2009, 2009, 1-6.

$82 \mathrm{M}$. Inouye, M. Ueno, T. Kitao and K. Tsuchiya, J. Am. Chem. Soc., 1990, 112, 8977-8979.

83 K. Kimura, T. Yamashita and M. Yokoyama, J. Chem. Soc., Perkin Trans. 2, 1992, 613-619.

84 M. Inouye, Y. Noguchi and K. Isagawa, Angew. Chem., Int. Ed. Engl., 1994, 33, 1163-1166.

85 C. Q. Tu, E. A. Osborne and A. Y. Louie, Tetrahedron, 2009, 65, $1241-1246$

86 K. Kimura, T. Teranishi, M. Yokoyama, S. Yajima, S. Miyake, H. Sakamoto and M. Tanaka, J. Chem. Soc., Perkin Trans. 2, 1999, 199-204.

87 T. Teranishi, M. Yokoyama, H. Sakamoto and K. Kimura, Mol. Cryst. Liq. Cryst., 2000, 344, 271-276.

88 M. Nakamura, T. Fujioka, H. Sakamoto and K. Kimura, New J. Chem., 2002, 26, 554-559.

89 H. Sakamoto, H. Takagaki, M. Nakamura and K. Kimura, Anal. Chem., 2005, 77, 1999-2006.

90 S. H. Liu, Mol. Cryst. Liq. Cryst., 2004, 419, 97-101.

91 S. Yagi, S. Nakamura, D. Watanabe and H. Nakazumi, Dyes Pigm., 2009, 80, 98-105.

92 J. Filley, M. A. Ibrahim, M. R. Nimlos, A. S. Watt and D. M. Blake, J. Photochem. Photobiol., A, 1998, 117, 193-198.

93 Z. L. Liu, L. Jiang, Z. Liang and Y. H. Gao, Tetrahedron, 2006, 62, 3214-3220.
94 N. Shao, Y. Zhang, S. M. Cheung, R. H. Yang, W. H. Chan, T. Mo, K. A. Li and F. Liu, Anal. Chem. 2005, 77, 7294-7303.

95 L. D. Taylor, J. Nicholso and R. B. Davis, Tetrahedron Lett., 1967, 1585-1588.

96 N. Shao, J. Y. Jin, H. Wang, Y. Zhang, R. H. Yang and W. H. Chan, Anal. Chem., 2008, 80, 3466-3475.

97 N. Shao, J. Y. Jin, S. M. Cheung, R. H. Yang, W. H. Chan and T. Mo, Angew. Chem., Int. Ed., 2006, 45, 4944-4948.

98 N. Shao, X. Gao, H. Wang, R. H. Yang and W. H. Chan, Anal. Chim. Acta, 2009, 655, 1-7.

99 N. Shao, H. Wang, X. D. Gao, R. H. Yang and W. H. Chan, Anal. Chem., 2010, 82, 4628-4636.

100 N. Shao, J. Y. Jin, H. Wang, J. Zheng, R. H. Yang, W. H. Chan and Z. Abliz, J. Am. Chem. Soc., 2010, 132, 725-736.

101 H. Gorner and A. K. Chibisov, J. Chem. Soc., Faraday Trans., 1998, 94, 2557-2564.

102 A. K. Chibisov and H. Gorner, Chem. Phys., 1998, 237, 425-442.

103 J. T. C. Wojtyk, P. M. Kazmaier and E. Buncel, Chem. Commun., 1998, 1703-1704.

104 M. Natali, C. Aakeroy, J. Desper and S. Giordani, Dalton Trans., 2010, 39, 8269-8277.

105 M. Natali, L. Soldi and S. Giordani, Tetrahedron, 2010, 66, 7612-7617.

106 M. Natali and S. Giordani, Org. Biomol. Chem., 2012, 10, $1162-1171$.

107 J. Q. Ren and H. Tian, Sensors, 2007, 7, 3166-3178.

108 S. L. Han and Y. Chen, Dyes Pigm., 2011, 88, 235-239.

109 M. Inouye, K. Kim and T. Kitao, J. Am. Chem. Soc., 1992, 114, 778-780.

110 M. Takase and M. Inouye, Chem. Commun., 2001, 2432-2433.

111 M. Tomasulo, S. Sortino, A. J. P. White and F. M. Raymo, J. Org. Chem., 2006, 71, 744-753.

112 M. Tomasulo and F. M. Raymo, Org. Lett., 2005, 7, 4633-4636.

113 L. Gobbi, P. Seiler and F. Diederich, Angew. Chem., Int. Ed., 1999, 38, 674-678. 